LA-14310

Approved for public release;

distribution is unlimited.

Selection of 3013 Containers for

Field Surveillance

- Los Alamos 
This project was funded by the U.S. Department of Energy, Environmental Management.

Los Alamos National Laboratory, an affirmative action/equal opportunity employer, is operated by Los Alamos National Security, LLC, for the National Nuclear Security Administration of the U.S. Department of Energy under contract DE-AC52-06NA25396.

This report was prepared as an account of work sponsored by an agency of the U.S. Government. Neither Los Alamos National Security, LLC, the U.S. Government nor any agency thereof, nor any of their employees make any warranty, express or implied, or assume any legal liability or responsibility for the accuracy, completeness, or usefulness of any information, apparatus, product, or process disclosed, or represent that its use would not infringe privately owned rights. Reference herein to any specific commercial product, process, or service by trade name, trademark, manufacturer, or otherwise does not necessarily constitute or imply its endorsement, recommendation, or favoring by Los Alamos National, LLC, the U.S. Government, or any agency thereof. The views and opinions of authors expressed herein do not necessarily state or reflect those of Los Alamos National Security, LLC, the U.S. Government, or any agency thereof. Los Alamos National Laboratory strongly supports academic freedom and a researcher's right to publish; as an institution, however, the Laboratory does not endorse the viewpoint of a publication or guarantee its technical correctness. 
LA-14310

Issued: January 2007

\section{Selection of 3013 Containers for}

\section{Field Surveillance}

Larry Peppers

Elizabeth Kelly

James McClard ${ }^{1}$

Gary Friday $^{1}$

Theodore Venetz ${ }^{2}$

Jerry Stakebake 3

${ }^{1}$ Washington Savannah River Company

${ }^{2}$ Fluor Hanford

${ }^{3}$ Navarro Research and Engineering, Inc.

\section{Los Alamos}




\section{MIS Working Group Concurrence}

(Signatures are on file.)

G.D. Roberson / DOE-AL

Richard Mason / Los Alamos National Laboratory
Date

Date

Date

Karen Dodson / Lawrence Livermore National Laboratory

James McClard / Savannah River Site

Date

Ted Venetz / Hanford Site

Date 


\section{Table of Contents}

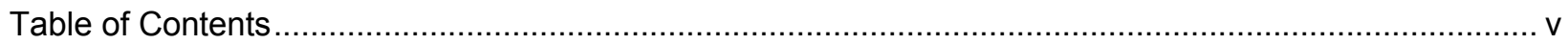

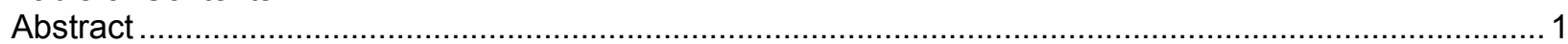

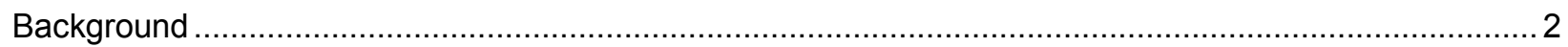

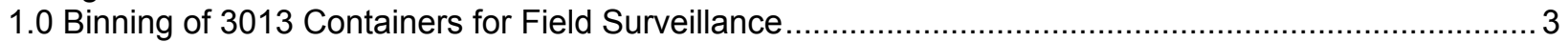

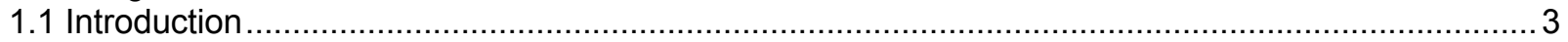

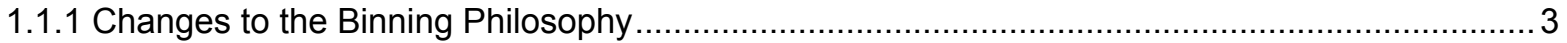

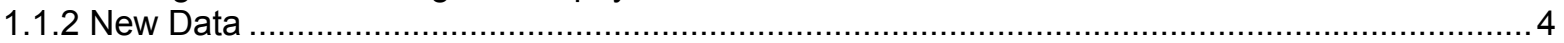

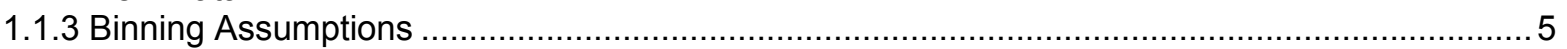

1.1.4 Determination of Best Available Moisture Measurement....................................................... 5

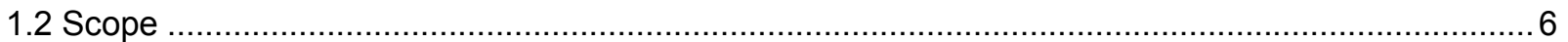

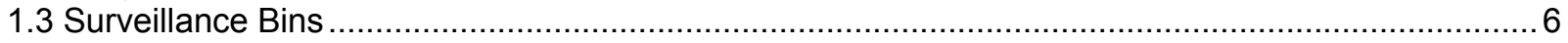

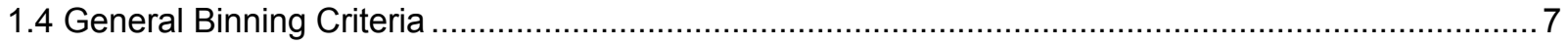

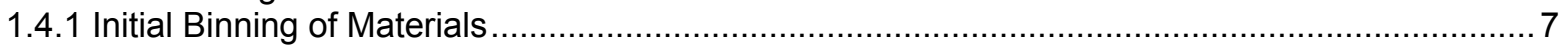

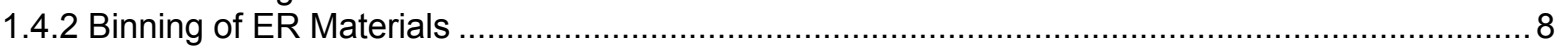

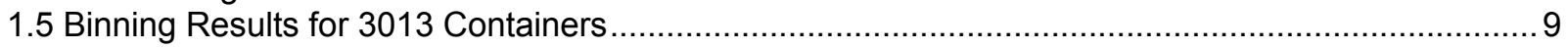

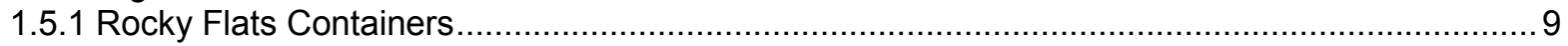

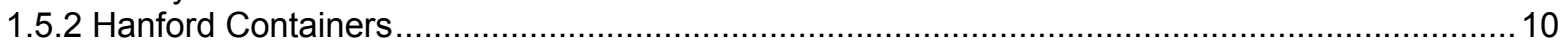

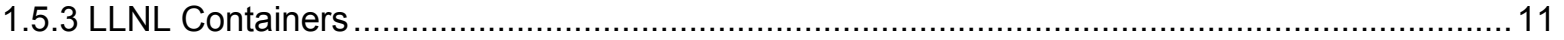

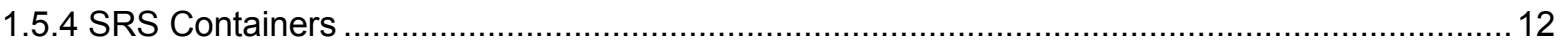

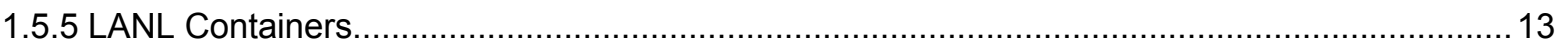

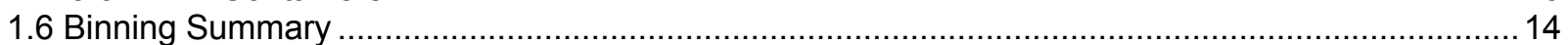

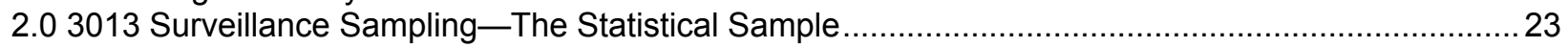

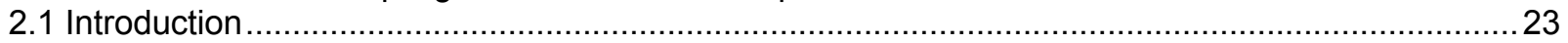

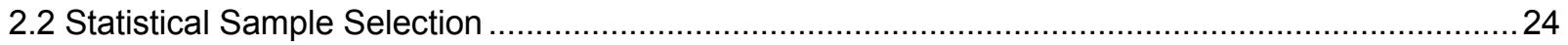

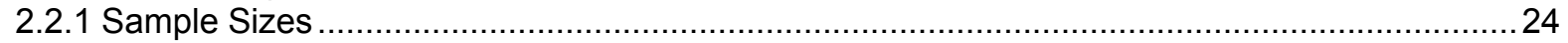

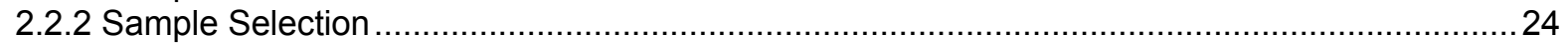

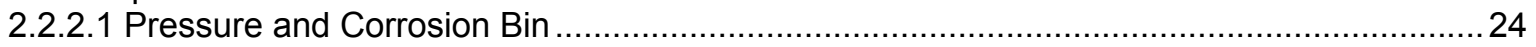

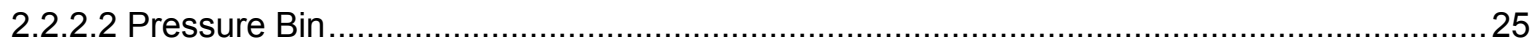

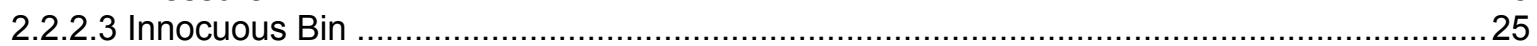

3.0 Selection of 3013 Containers for Field Surveillance-Statistical and Judgmental Samples ...............27

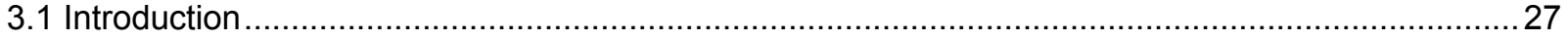

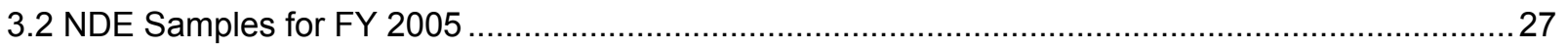

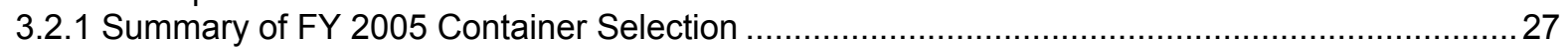

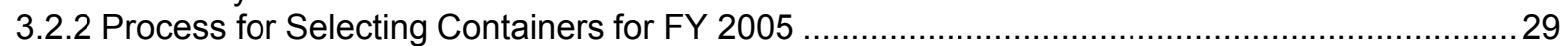

3.2.3 Selection of Containers Based on Engineering Judgment .................................................. 30

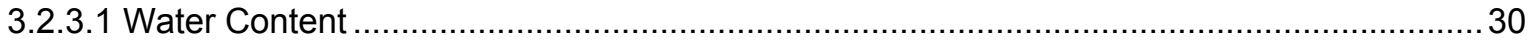

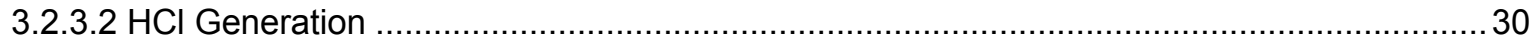

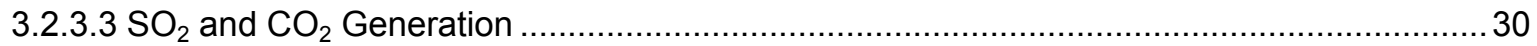

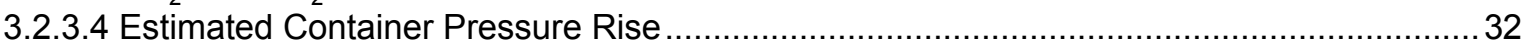

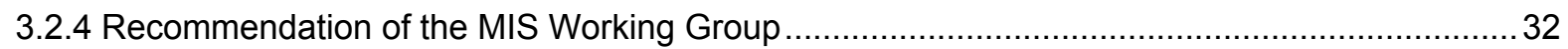

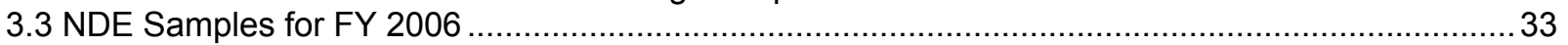

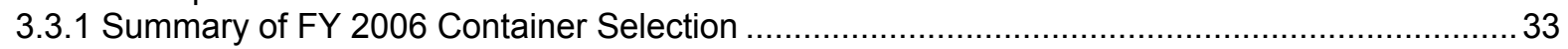

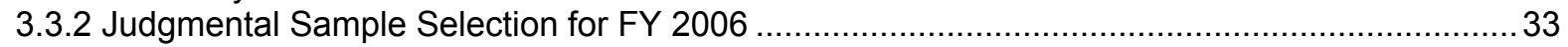

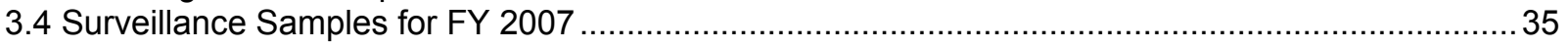

3.4.1 Summary of FY 2007 Container Selection ................................................................... 35

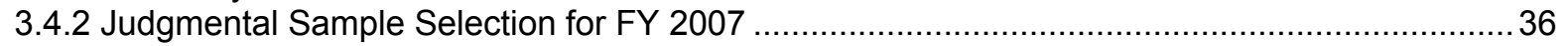

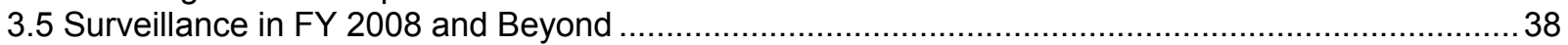

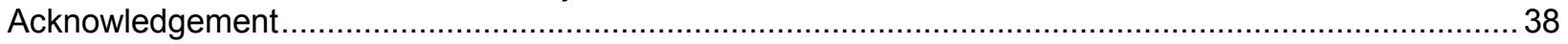

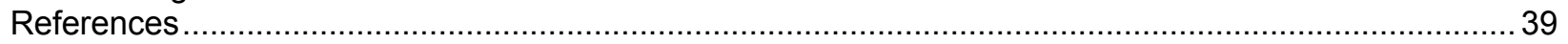

Appendix A-Random Sample Based on FY 2006 Rebinning ..................................................... A-1

Table A-1 - Pressure and Corrosion Bin Random Sample ........................................................ A-1

Table A-2 - Pressure Bin Random Sample ..................................................................... A-4

Table A-3 - Innocuous Bin Random Sample ......................................................................... A-7 


\title{
Selection of 3013 Containers for Field Surveillance
}

\author{
by \\ Larry Peppers, Elizabeth Kelly, James McClard, Gary Friday, Theodore Venetz, and Jerry Stakebake
}

\begin{abstract}
This report revises and combines three earlier reports ${ }^{1-3}$ dealing with the binning, statistical sampling, and sample selection of 3013 containers for field surveillance. It includes changes to the binning specification resulting from completion of the Savannah River Site packaging campaign and new information from the shelf-life program and field surveillance activities. The revised bin assignments result in changes to the random sample specification. These changes are necessary to meet the statistical requirements of the surveillance program. This report will be reviewed regularly and revised as needed.
\end{abstract}

Section 1 of this report summarizes the results of an extensive effort to assign all of the current and projected 3013 containers in the Department of Energy (DOE) inventory to one of three bins (Innocuous, Pressure and Corrosion, or Pressure) based on potential failure mechanisms. Grouping containers into bins provides a framework to make a statistical selection of individual containers from the entire population for destructive and nondestructive field surveillance. The binning process consisted of three main steps. First, the packaged containers were binned using information in the Integrated Surveillance Program database and a decision tree. The second task was to assign those containers that could not be binned using the decision tree to a specific bin using container-by-container engineering review. The final task was to evaluate containers not yet packaged and assign them to bins using process knowledge. The technical basis for the decisions made during the binning process is included in Section 1. A composite decision tree and a summary table show all of the containers projected to be in the DOE inventory at the conclusion of packaging at all sites. Decision trees that provide an overview of the binning process and logic are included for each site.

Section 2 of this report describes the approach to the statistical selection of containers for surveillance and consists of a revision of the earlier statistical sampling report. ${ }^{2}$ The requirement of $99.9 \%$ probability of observing at least one of the worst $5 \%(99.9 / 5 \%)$ of the containers with a potential for degradation is used to determine the number of containers in the random sample for the Pressure and Corrosion and the Pressure bins. Sampling requirements for the Innocuous bin are not based on the $99.9 / 5 \%$ requirement; rather, they are based on evaluating the assumption of no significant degradation of, or variability between, containers relative to corrosion or pressure generation within the Innocuous bin population as valid.

Section 3 of this report focuses on the actual selection of 3013 containers for surveillance. Surveillance containers are identified by the year that the surveillance should be performed. In addition to the randomly selected containers, containers were selected from the entire population, based on engineering judgment for each of these years. The judgmental sampling targets containers with the greatest potential for gas generation and/or corrosion. The factors used for judgmental sample selection are documented in this section. A more detailed discussion of the FY 2005 sample selection process is contained in the previous FY 2005 sample selection report. ${ }^{3}$ 


\section{Background}

The U.S. nuclear weapons program has generated large quantities of excess plutonium. This material must be safely stored pending final disposition. Requirements for packaging and storage of plutonium-bearing materials have been addressed in the Department of Energy (DOE) Standard, "Stabilization, Packaging, and Storage of Plutonium-Bearing Materials," DOE-STD3013, ${ }^{4}$ and are being implemented throughout the DOE complex. In order to ensure the safe storage of plutonium in 3013-type containers, the 3013 standard directed that a surveillance plan be developed and used for monitoring the condition of these containers during storage. DOE has implemented an Integrated Surveillance Program (ISP) ${ }^{5}$ that is designed to integrate individual sites into a corporate, cost-effective surveillance effort. The ISP consists of two independent programs: the Shelf-Life program to closely monitor the behavior of selected materials under laboratory conditions and the Field Surveillance program to destructively and nondestructively evaluate production 3013 containers and materials during storage.

The Surveillance and Monitoring Plan for DOE-STD-3013 materials ${ }^{6}$ (S\&M Plan) outlines a statistical sampling approach for the surveillance of 3013 packaged containers. In addition to the statistical sampling, other containers may be added to the surveillance containers based on engineering judgment. ${ }^{3}$ For the statistical sampling portion of the program, the ISP Steering Committee has directed that, with a $99.9 \%$ probability, at least one from the worst $5 \%(99.9 / 5 \%$ criteria) of the pressure-generating or corrosive containers in a defined population is evaluated during the random portion of the surveillance program. To facilitate selection and surveillance, the 3013 containers are binned based on the mechanisms that could potentially challenge the container. The bins are defined as Innocuous, Pressure, and Pressure and Corrosion. During the binning process, containers that were not categorized well enough to be placed in one of the bins using a binning decision tree required a container-by-container Engineering Review (ER).

The purpose of this report is to describe the process used in binning containers and to document the results from binning all packaged 3013 containers as well as those containers not yet packaged. Although this report emphasizes packaged containers, unprocessed items from Los Alamos National Laboratory (LANL) and Lawrence Livermore National Laboratory (LLNL) are also addressed (Section 1). This report then describes the statistical selection of containers in the Pressure bin and Pressure and Corrosion bin to achieve the $99.9 / 5 \%$ criteria. Sampling of the Innocuous bin was used to confirm the binning assumption of no significant degradation of or variability between the containers relative to corrosion or pressure generation (Section 2). The report then focuses on statistical and judgmental sample selection of containers for nondestructive (NDE) and destructive evaluation (DE) for the first three years of the field surveillance program and defines a schedule for statistical sample selection for the out-years of the field surveillance program (Section 3). 


\subsection{Binning of 3013 Containers for Field Surveillance}

\subsection{Introduction}

Revisions to the bin assignment of containers made in Section 1 of this report are the result of several changes in the binning philosophy from the original report ${ }^{1}$ and the inclusion of new data. Changes include the completion of the Savannah River Site (SRS) 3013 packaging effort, reanalysis of Rocky Flats Environmental Technology Site (Rocky Flats or RFETS) Fourier transform infrared spectroscopy (FTIR) moisture data, use of the best available moisture data in the binning decision, inclusion of additional prompt gamma analysis, revising the prompt gamma fluoride concentration used to determine potentially corrosive containers to match the minimum detectible chloride concentration, inclusion of chemical analysis results from some Hanford and SRS containers, and revising the criteria for a container to be considered Innocuous. These changes are reflected in the revised binning decision trees, Figures 1.1 through 1.7, and are discussed in further detail below.

\subsubsection{Changes to the Binning Philosophy}

Better moisture data are now available for some of the Rocky Flats and Hanford containers (see Section 1.1.4 below). Reevaluation of the Rocky Flats FTIR data provided more accurate moisture results for all of the FTIR measurements. ${ }^{7}$ Previously, in cases where the Thermogravimetric Analysis (TGA) result met the acceptance criteria, TGA was used as the certification moisture value and as the basis for the binning decision even when FTIR results were available. For cases where the FTIR result was used for certification, the reevaluated FTIR moisture value is considered more accurate. In both cases, the reevaluated FTIR result is now used for binning decisions.

Some Hanford convenience cans gained weight in storage before packaging into inner containers. In the original binning report, ${ }^{1}$ these weight gains were not included in the ISP database $^{8}$ and were not part of the binning decisions. The current ISP database now includes the Hanford weight gain data. The weight gain during interim storage has been added to the measured moisture result and is included in the database as the best estimate of moisture in the container. The assumption is that any weight gain during storage is attributed to the material adsorbing moisture.

The limit of detection for fluoride $(0.1 \mathrm{wt} \%)$ by prompt gamma analysis is lower than for chloride $(0.8 \mathrm{wt} \%)$. In addition, at a given concentration, chloride has a higher potential for corrosion of the container. This difference in detection limits places a disproportionately large number of low fluoride $(<0.8 \mathrm{wt} \%)$ containers in the Pressure and Corrosion bin, thus diluting the bin population. Using the fluoride assumption in section 1.3 below, containers with less than $0.8 \mathrm{wt} \%$ fluorides have been removed from the Pressure and Corrosion bin.

Containers were previously considered to be Innocuous when they passed all tests in the decision tree and did not require an engineering review. This allowed containers without prompt gamma or chemistry analysis to automatically be placed into the Innocuous bin. Containers without prompt gamma or chemistry analysis are now required to have an engineering review before they 
are considered innocuous. Also, containers with detected low fluoride are required to go though engineering review before being considered innocuous.

Revisions were made as to which material groups are considered corrosive by process knowledge. Process knowledge assumptions of which material groups contained chlorides and fluorides were validated using prompt gamma results and other historical information; the only material groups that are considered inherently corrosive are as follows:

- Hanford represented group "Impure and scrap oxides from Rocky Flats" (1E) or "Impure and scrap Pu oxides with 30-80 wt\% Pu PFP generated scrap oxides" (2B) that do not have prompt gamma analysis,

- Rocky Flats group "Pyrochemical — byproduct oxides" (2B) or "Screenings from Pu oxidation - byproduct oxides" (2E),

- SRS materials from Rocky Flats origin that are identified as ARF material in the SRS group $^{11}$ "Metal oxidation from Rocky Flats (foundry oxide, 80-85 wt\%)" (1A), and

- Containers from LLNL with any portion of washed material in the container

The LLNL containers mentioned in the final bullet were considered corrosive because many of the LLNL containers with washed material still showed significant amounts of chloride as measured by prompt gamma. ${ }^{12}$ As a conservative approach, these containers are considered corrosive.

\subsubsection{New Data}

SRS has now completed their 3013 packaging campaign. SRS packaged a total of 920 containers, which included 618 containers of metal and 302 containers of oxide. This is 120 containers less than what was projected in the original binning report ${ }^{1}$ and includes two fewer metal containers and 118 fewer oxide containers.

Chemical analysis data for several Hanford and SRS containers have been added to the ISP database and are now available for use in binning decisions. Thirteen containers were identified from these data as having greater than $1,000 \mathrm{ppm}$ chloride or greater than $8,000 \mathrm{ppm}$ fluoride (analysis results reported in units of ppm are equivalent to results reported in $\mu \mathrm{g} / \mathrm{g}$ in most cases).

More prompt gamma analyses have been completed and are available for binning decisions. ${ }^{13}$ Additional prompt gamma results are available from SRS containers as required as part of the certification. Additional Hanford prompt gamma analyses were performed on containers that previously lacked prompt gamma results. Also, Rocky Flats containers that were part of the FY 2005 nondestructive surveillance program at SRS were remeasured by prompt gamma using 60 -minute count times instead of the 15-minute count times originally used at Rocky Flats. The longer count time provided better lower detection limits for chloride and fluoride. These additional prompt gamma results are now used in place of process knowledge and previously available prompt gamma results for use in binning of these containers. In the case of the more sensitive analysis performed on Rocky Flats containers, prompt gamma analysis detected chloride in several containers where previous analysis showed none. In one case, chloride was not found in the 60-minute reanalysis but was detected in the original 15 -minute analysis. In this case, the more conservative analysis (chloride present) is used. 


\subsubsection{Binning Assumptions}

The following conditions are assumed and form the basis for all binning decisions:

- Metal containers without loosely adhering oxide are innocuous, based on historical and scientific data. ${ }^{14-15}$

- Chloride salts and high concentrations of fluoride salts are potentially corrosive to types 304 and 316 stainless steels. ${ }^{16-17}$

- Chloride poses greater risk of corrosion than fluoride at the same concentration. ${ }^{18}$

- Pressurization of containers in the Pressure and Corrosion bin is primarily caused from radiolysis of water to generate hydrogen gas (other gases may be generated but in minor amounts relative to hydrogen). ${ }^{19}$

- Pressurization of containers in the Pressure bin is due to a combination of factors, including the radiolysis of water to generate hydrogen gas and the generation of other gases such as $\mathrm{O}_{2}, \mathrm{~N}_{2}, \mathrm{NO}_{2}, \mathrm{SO}_{2}, \mathrm{CO}_{2}, \mathrm{CO}$, and $\mathrm{CH}_{4}$ (the mechanisms for generation of these other gases are not well understood but may contribute a substantial percentage of the total pressure). ${ }^{19}$

- The amount of water present directly affects the maximum potential pressure in a container from the radiolysis of water. ${ }^{4}$

- Containers with less than $0.8 \mathrm{wt} \%$ fluoride are assumed not to be in the worst $5 \%$ of the Pressure and Corrosion bin population based on the fluoride level alone.

- Containers with chloride at levels below the prompt gamma detection threshold are assumed not to be in the worst 5\% of the Pressure and Corrosion bin population.

- Containers with high-purity oxide containing less than $0.1 \mathrm{wt} \%$ water are assumed not to be in the worst $5 \%$ of the population based on pressure generation.

\subsubsection{Determination of Best Available Moisture Measurement}

Moisture analysis methods vary in their accuracy to measure moisture exclusive of other effects. Loss on ignition (LOI) and TGA are generally recognized to be conservative because of measurement of weight loss of more than the water present. Coupling the TGA analysis with either FTIR or mass spectroscopy (MS) is more specific to measurement of only the water in the sample.

LOI and TGA methods measure any weight change to the sample when heated to $1,000^{\circ} \mathrm{C}$. Weight change can be due to loss of water or evaporation of salts or because of the oxidation of other materials present (e.g., carbon or uranium). The main difference between LOI and TGA is when the final weight of the sample is measured. For LOI analysis, the sample is weighed at room temperature (or generally below $100^{\circ} \mathrm{C}$ ), but it is measured at $1,000^{\circ} \mathrm{C}$ when using TGA analysis. Readsorption of water during cooling of the LOI samples masks the actual weight loss of the sample, which is the basis for using a lower $0.05 \mathrm{wt} \%$ binning cutoff for the LOI analysis compared to $0.10 \mathrm{wt} \%$ for all other methods.

Because some containers were stored for significant amounts of time between sampling for moisture analysis and welding into inner containers, weight change (gain) during storage was interpreted as moisture adsorbed by the material. Where applicable, weight gain during storage is added to the moisture measurement (from any of the methods) and is used as a better representation of the moisture in a container than the moisture measurement alone. 
Rocky Flats containers measured with FTIR analysis were subject to reevaluation of the moisture result because of changes in the way the FTIR baseline was measured and subtracted. The revised baseline subtraction improved the accuracy of the moisture result, and the recalculated result is considered better than the originally reported value. ${ }^{7}$ A significant portion of the Rocky Flats containers used the TGA analysis as the certification value, but also had FTIR analysis results available. In these cases, the FTIR analysis (specifically, the recalculated FTIR analysis) is considered the most accurate or best moisture value.

For containers having more than one moisture value, the preferred analytical method is listed below in order of decreasing accuracy:

1. Recalculated FTIR analysis

2. FTIR or MS

3. TGA

4. LOI

In addition, if a convenience can showed a storage weight gain, adding the weight gain to any of the above analyses is better than using an analysis alone. The ISP database contains all moisture measurement results for any container and has a pointer to the best available result.

\subsection{Scope}

The scope of Section 1 consisted of a three-tiered review of all 3013 containers with the primary objective of placing each container into one of the three bins for the purpose of surveillance.

Tier 1 - Containers that have already been packaged and have been assigned to their appropriate surveillance bins based on information in the data package provided for each container using the binning decision tree Figure 1-1.

Tier 2 - Containers from Rocky Flats, Hanford, SRS, and LLNL that are currently packaged and have failed the initial screening for immediate assignment to a surveillance bin required an engineering review before they were assigned to an appropriate bin. Containers in this tier were individually reviewed before assignment to one of the three surveillance bins.

Tier 3-Items not yet packaged from LLNL and LANL. Some of these items can easily be binned based on being either metal or an oxide with greater than $85 \mathrm{wt} \%$ plutonium $(\mathrm{Pu})$. The remainder required a somewhat subjective and conservative engineering review before assigning them to a bin for surveillance. Assigning items in this group to bins at this time only serves to provide total bin estimates for the purpose of defining the total number of samples required in the surveillance program.

\subsection{Surveillance Bins}

Containers in the 3013 inventory are initially sorted according to the potential failure mechanism that they may present, i.e., pressure generation, corrosion plus pressure generation, or neither. The three bins or indicator populations used for sorting are Pressure, Pressure and Corrosion, and 
Innocuous. Moisture is needed to create the potential for pressurization. A corrosive classification, although useful for isolating a failure mechanism, is tied to the pressure-generating classification because moisture is also needed to form the corrosive electrolyte and is identified by the classification of Pressure and Corrosion. The Innocuous bin is used for containers that have no potential for either pressurization or corrosion. Metals and high-purity oxides with low moisture are generally considered Innocuous. ${ }^{14-15}$ These three bins or strata form the initial indicator populations that are used to sort containers for different levels of surveillance. Binning was accomplished using the decision tree shown in Figure 1.1. Information to facilitate the binning came primarily from the ISP database that contains all of the information from the Product Certification Databases (PCD) generated by the packaging sites as well as additional data from other sources such as small and large-scale testing or reevaluation of existing data present in the database (e.g., moisture data). The ISP database includes information such as process knowledge regarding the source of the material, moisture content of the material, prompt gamma analytical data taken after packaging, and chemical analysis data. The decision tree is set up to bin metal containers, oxide containers with corrosive impurities, pure oxides (containing greater than $85 \mathrm{wt} \% \mathrm{Pu}+\mathrm{Am}+\mathrm{Np}$ ), and impure oxides with greater than a threshold moisture content using the database information. Impure oxides with less than the threshold moisture content $(0.05 \mathrm{wt} \%$ LOI or $0.10 \mathrm{wt} \% \mathrm{TGA} / \mathrm{FTIR} / \mathrm{MS})$ were required to go through the process of ER before appropriate bin assignments could be made.

\subsection{General Binning Criteria}

\subsubsection{Initial Binning of Materials}

The initial binning evaluation assigned containers with only Pu metal plus any associated metal impurities to the Innocuous bin, as illustrated by the decision tree (Figure 1.1). The second binning operation was to separate containers with a potential for corrosion. The primary constituent for causing corrosion is chloride salts or possibly fluoride-containing materials. Using information supplied in the database, containers identified as containing either chloride (greater than 1,000 ppm) or fluoride (greater than 8,000 ppm) were placed in the Pressure and Corrosion bin. Identification of chloride or fluoride could be accomplished by chemical analysis, prompt gamma analysis, or process knowledge of the material. These methods for determining the presence of corrosive materials have varying degrees of accuracy and sensitivity. For example, using process knowledge alone, the 3013 container may or may not contain chlorides or fluorides. If items in the container originated from a process that used chlorides, it was placed in the Pressure and Corrosion bin unless there was additional analytical information to the contrary. If the chemical analysis showed chloride greater than $1,000 \mathrm{ppm}$ or fluoride greater than $8,000 \mathrm{ppm}$ or if the prompt gamma analysis detected either chloride (any positive detection) or fluoride greater than or equal to $0.8 \mathrm{wt} \%(8,000 \mathrm{ppm})$, the container was placed in the Pressure and Corrosion bin. The prompt gamma detection limit for chlorine is about $0.8 \mathrm{wt} \%$, and the detection limit for fluorine is about $0.1 \mathrm{wt} \% .^{12}$

The third criterion, used for the binning of pure oxide material that showed no evidence for containing corrosive materials, was the final moisture content of the oxide. The DOE-STD-3013 sets the moisture limit for oxide materials at $0.5 \mathrm{wt} \%$. However, the actual acceptance limit for moisture content varied from site to site depending on the method for moisture analysis and the date the container was generated. To accommodate the different acceptance values for each site, 
a conservative moisture limit was established for binning of the pure oxide materials. Containers with an LOI result greater than $0.05 \mathrm{wt} \%$ were assigned to the Pressure bin. When moisture was measured by TGA, FTIR, or MS, a moisture limit of greater than or equal to $0.10 \mathrm{wt} \%$ was established for placing the container in the Pressure bin. Containers with pure oxide with moisture content below these limits were placed in the Innocuous bin unless the fluoride or prompt gamma exception applied.

If a container successfully passed the screening test for Pressure and Corrosion as well as for Pressure, and had less than $85 \mathrm{wt} \%(\mathrm{Pu}+\mathrm{Am}+\mathrm{Np})$, it required an ER to evaluate each container individually.

\subsubsection{Binning of ER Materials}

All containers selected for ER have been prescreened as described above (with the exception of those not yet packaged) using the logic diagram shown in Figure 1.1. All packaged containers have a $\mathrm{Pu}+\mathrm{Am}+\mathrm{Np}$ content of less than $85 \mathrm{wt} \%$ (or meet the low fluoride or prompt gamma exception) with no known chloride content from process knowledge or analytical analyses and have a moisture content of less than $0.05 \mathrm{wt} \%$ by LOI or less than $0.1 \mathrm{wt} \%$ by TGA and/or FTIR/MS. Uranium was excluded from the prescreening process because its large measurement uncertainty could skew the binning results. However, the presence of uranium was considered during the ER. The criteria for binning ER containers are listed below.

Criterion 1: Containers with greater than $85 \mathrm{wt} \% \mathrm{Pu}+\mathrm{Am}+\mathrm{Np}+\mathrm{U}$ (total actinide) were placed in the Innocuous bin. These containers were reviewed on an individual basis to ensure that the material came from a historically pure stream so that the uranium measurement uncertainty could not cause an impure material to be binned as innocuous.

Criterion 2: Containers with total actinide content between 80 and $85 \mathrm{wt} \%$ were reviewed on an individual basis. Those containers from a process that historically produced pure material with a moisture content of less than $0.05 \mathrm{wt} \%$ were placed in the Innocuous bin unless there was a suspected problem with the moisture analysis identified through a nonconformance report (NCR) or other documented production comment. Containers not meeting the moisture criteria were placed in the Pressure bin.

The only exception to the $0.05 \mathrm{wt} \%$ criterion was for mixed plutonium-uranium oxide containers processed in the Stabilization Packaging Equipment (SPE) dry line at Hanford that had a TGA moisture value exceeding $0.05 \mathrm{wt} \%$. The TGA results were reviewed on an individual basis to determine if excess weight loss occurred at high temperatures and could be attributed to oxygen loss from the uranium oxide and not water. For these cases, the container was placed in the Innocuous bin.

Criterion 3: Containers with a total actinide content of less than $80 \mathrm{wt} \%$ were placed in the Pressure bin. (Exceptions were oxide containers evaluated under Criterion 4.)

Criterion 4: Oxide containers produced by magnesium hydroxide precipitation from pure plutonium nitrate solutions represent a special class of items where the major impurity is magnesium oxide and prompt gamma indicates no other significant impurities. 
Hanford-Containers from Hanford packaged in the SPE (dry) line and having a TGA moisture content of less than $0.05 \mathrm{wt} \%$ were placed in the Innocuous bin. All others were placed in the Pressure bin.

Rocky Flats-Containers from Rocky Flats must have a TGA value of less than $0.05 \mathrm{wt} \%$, and the glovebox moisture content at the time of packaging must be less than $1,000 \mathrm{ppm}$. Containers meeting these criteria were placed in the Innocuous bin. All others were placed in the Pressure bin. Containers suspected to have originated from other than pure plutonium nitrate, e.g., $\mathrm{Pu} / \mathrm{U}$ solutions, were evaluated using Criteria 1, 2, or 3 .

Criterion 5: This criterion applied only to Rocky Flats containers; similar data are not available from other sites. During the moisture analysis using TGA/FTIR, evaluation of the FTIR data indicated the presence of hydrogen chloride $(\mathrm{HCl})$ in some samples. ${ }^{20}$ $\mathrm{HCl}$ was found to occur in three temperature ranges: $20^{\circ} \mathrm{C}-350^{\circ} \mathrm{C}, 350^{\circ} \mathrm{C}-670^{\circ} \mathrm{C}$; and $670^{\circ} \mathrm{C}-1,000^{\circ} \mathrm{C}$. However, only the $\mathrm{HCl}$ values in the low temperature range are important to the material storage temperatures because the material temperatures are not expected to exceed $350^{\circ} \mathrm{C}$. A total of 36 containers with low temperature $\mathrm{HCl}$ have been found in the Rocky Flats inventory with four of those containers in the ER category. This analytical method is very sensitive and possibly subject to contamination from other chloride-bearing samples. However, taking a very conservative approach, all 36 containers were placed in the Pressure and Corrosion bin. It is highly likely that other sites have materials that would exhibit this property; but these could not be evaluated and were left in their predetermined bins.

\subsection{Binning Results for 3013 Containers}

\subsubsection{Rocky Flats Containers}

A total of 1,888 containers from Rocky Flats required binning (Table 1.1). Of this total, 1,546 containers were binned using the decision tree in Figure 1.1, and 342 containers were binned using the ER criteria described in section 1.4.2 above. Table 1.1 and Figure 1.3 summarize the binning results. The "ISP Sub Bin" column in Figure 1.1 refers to the decision criteria used to make the binning decision and is composed of three parts. The first part refers to the decision method used for binning, either BDT (binning decision tree) for containers that were directly binned or ER for containers that required individual review (see Figure 1.1). The second part refers to the decision block in the tree for containers starting with BDT or the ER criteria (see section 1.4.2) for containers starting with ER. The third part shows descriptors that specify the details of the decision as well as the binning result, "I" for Innocuous or "P" for Pressure where appropriate (e.g., "BDT-3-Cl-HCl" refers to containers that contained chlorine by prompt gamma and also showed $\mathrm{HCl}$ by FTIR analysis that is part of Criteria 5, and "ER-C2-P (Low F)" refers to low fluoride containers individually reviewed using Criteria 2 but did not meet the criteria to be considered Innocuous and where therefore assigned to the Pressure bin).

Of the 342 ER containers reviewed, 167 were assigned to the Innocuous bin, 171 to Pressure, and 4 to Pressure and Corrosion. The composite binning of all 1,888 Rocky Flats 3013 
Table 1.1 Rocky Flats Binning Summary

\begin{tabular}{|l|l|l|}
\hline ISP Bin & ISP Sub Bin & Total \\
\hline Innocuous & BDT-1 & 581 \\
& BDT-6 & 60 \\
& ER-BDT-6-I (Low F) & 11 \\
& ER-BDT-6-I (No PG) & 3 \\
& ER-C1-I & 34 \\
& ER-C1-I (No PG) & 3 \\
& ER-C2-I & 28 \\
& ER-C2-I (Low F) & 11 \\
& ER-C2-I (No PG) & 4 \\
& ER-C4-I & 73 \\
\hline Innocuous Total & & 808 \\
\hline Pressure & BDT-5 & 550 \\
& ER-C1-P & 6 \\
& ER-C1-P (Low F) & 1 \\
& ER-C1-P (No PG) & 2 \\
& ER-C2-P & 16 \\
& ER-C2-P (Low F) & 3 \\
& ER-C2-P (No PG) & 1 \\
& ER-C3 & 107 \\
& ER-C3 (Low F) & 27 \\
& ER-C3 (No PG) & 1 \\
& ER-C4-P & 7 \\
\hline Pressure and Corrosion Total & & 721 \\
\hline Rocky Flats Total & & 212 \\
\hline \multicolumn{1}{|l}{ Pressure Total } & & 32 \\
\hline Pressure and Corrosion & BDT-3-Cl & 65 \\
& BDT-3-Cl-HCl & 2 \\
& BDT-3-F & 44 \\
& BDT-3-F-HCl & 3 \\
& BDT-4-RF-2B & 1 \\
\hline & ER-C5-HCl & 359 \\
\hline
\end{tabular}

containers dispositioned 808 containers to Innocuous, 721 to Pressure, and 359 to Pressure and Corrosion.

\subsubsection{Hanford Containers}

A total of 2,257 containers from Hanford required binning. Of this total, 1,701 containers were binned directly using the decision tree in Figure 1.1, and 556 containers were binned using the ER criteria listed in section 1.4.2. Prompt gamma data were unavailable for 362 containers in the Hanford inventory. When prompt gamma analysis is complete, some containers may need to be moved to the Pressure and Corrosion bin from either the Pressure or Innocuous bins. Table 1.2 and Figure 1.4 summarize the binning results. 
Table 1.2 Hanford Binning Summary

\begin{tabular}{|l|l|l|}
\hline ISP Bin & ISP Sub Bin & Total \\
\hline Innocuous & BDT-1 & 310 \\
& BDT-6 & 166 \\
& ER-BDT-6-I (Low F) & 6 \\
& ER-BDT-6-I (No PG) & 268 \\
& ER-C1-I & 42 \\
& ER-C1-I (No PG) & 5 \\
& ER-C2-E-I & 15 \\
& ER-C2-I & 22 \\
& ER-C2-I (Low F) & 1 \\
& ER-C2-I (No PG) & 26 \\
& ER-C4-I & 26 \\
& ER-C4-I (No PG) & 34 \\
\hline & & 921 \\
\hline Innocuous Total & BDT-5 & 635 \\
\hline Pressure & ER-BDT-6-P (No PG) & 2 \\
& ER-C2-E-P & 4 \\
& ER-C2-P & 21 \\
& ER-C2-P (Low F) & 4 \\
& ER-C2-P (No PG) & 18 \\
& ER-C3 & 28 \\
& ER-C3 (Low F) & 20 \\
& ER-C3 (No PG) & 9 \\
& ER-C4-P & 1 \\
& ER-C4-P (No PG) & 4 \\
\hline Pressure and Corrosion Total & & 746 \\
\hline Hanford Total & BDT-4-H-2B & 10 \\
\hline \multicolumn{5}{|l}{ Pressure Total } & & 3 \\
\hline Pressure and Corrosion & BDT-2-Cl & 324 \\
& BDT-2-F & 64 \\
& BDT-3-Cl & 121 \\
& BDT-3-F & 68 \\
\hline & BDT-4-H-1E & 590 \\
\hline
\end{tabular}

Of the 556 ER containers reviewed, 445 were assigned to the Innocuous bin, 111 to Pressure, and none to Pressure and Corrosion. The composite binning of all 2,257 Hanford 3013 containers dispositioned 921 containers to Innocuous, 746 to Pressure, and 590 to Pressure and Corrosion.

\subsubsection{LLNL Containers}

LLNL anticipates producing a total of 135 containers containing both metal and oxide. To date, 74 containers have been packaged. Some of the oxide items containing chloride salts from pyrochemical processing were given an aqueous wash to remove the chloride. However, the prompt gamma spectra showed that at least $0.8 \mathrm{wt} \%$ chloride or fluoride still remains in some of the washed items. ${ }^{12}$

Binning decisions for both the packaged and the projected number of unpackaged containers were made using the binning decision tree. All containers produced from the chloride wash 
Table 1.3 LLNL Binning Summary for Existing Containers

\begin{tabular}{|l|l|l|}
\hline ISP Bin & ISP Sub Bin & Total \\
\hline Innocuous & BDT-1 & 6 \\
& BDT-6 & 1 \\
& ER-C2-I & 2 \\
\hline Innocuous Total & & 9 \\
\hline Pressure & ER-C3 & 5 \\
& ER-C3 (Low F) & 4 \\
\hline Pressure Total & 9 \\
\hline Pressure and Corrosion & BDT-3-Cl & 8 \\
& BDT-3-F & 2 \\
& BDT-4 (LLNL Washed) & 46 \\
\hline Pressure and Corrosion Total & 56 \\
\hline LLNL Total & 74 \\
\hline
\end{tabular}

process were conservatively placed in the Pressure and Corrosion bin based on post-washing prompt gamma results. The 61 unpackaged containers received the most conservative evaluation and were placed in the Pressure and Corrosion bin. Table 1.3 and Figure 1.5 summarize the binning results.

The composite binning of all 135 processed and projected LLNL 3013 containers dispositioned nine containers to Innocuous, nine to Pressure, and 117 to Pressure and Corrosion.

\subsubsection{SRS Containers}

A total of 920 containers from SRS required binning. Of this total, 867 containers were binned directly using the decision tree in Figure 1.1, and 53 containers were binned using the ER criteria described in section 1.4.2. Table 1.4 and Figure 1.6 summarize the binning results.

A number of containers sent to SRS from Rocky Flats were binned in the Pressure and Corrosion bin based on process knowledge information provided by SRS that was not included the database. These containers were from material in the ARF group that was processed as stabilization runs PS-212 through PS-271.

Of the 53 ER containers reviewed, 46 were assigned to the Innocuous bin, seven to Pressure, and none to Pressure and Corrosion. The composite binning of the 920 SRS 3013 containers dispositioned 746 containers to Innocuous, 103 to Pressure, and 71 to Pressure and Corrosion. 
Table 1.4 SRS Binning Summary

\begin{tabular}{|l|l|l|}
\hline ISP Bin & ISP Sub Bin & Total \\
\hline Innocuous & BDT-1 & 618 \\
& BDT-6 & 82 \\
& ER-BDT-6-I (Low F) & 4 \\
& ER-BDT-6-I (No PG) & 22 \\
& ER-C1-I & 16 \\
& ER-C2-I & 4 \\
\hline Innocuous Total & & 746 \\
\hline Pressure & BDT-5 & 96 \\
& ER-C2-P & 1 \\
& ER-C2-P (Low F) & 2 \\
& ER-C3 & 3 \\
& ER-C3 (Low F) & 1 \\
\hline Pressure Total & & 103 \\
\hline Pressure and Corrosion & BDT-3-Cl & 18 \\
& BDT-3-F & 14 \\
& BDT-4-SR-ARF & 39 \\
\hline Pressure and Corrosion Total & & 71 \\
\hline SRS Total & & 920 \\
\hline
\end{tabular}

\subsubsection{LANL Containers}

Stabilization and packaging of oxides at LANL has begun. As of June 2006, approximately 40 convenience cans have been packaged into inner containers, and of those, none have been certified as meeting all of the 3013 requirements, and none have been packaged into outer 3013 containers. For surveillance purposes, an estimate was made of the total number of 3013 containers to be produced using the Los Alamos National Laboratory Implementation Plan. ${ }^{21}$ It was assumed that each 3013 container would hold $3 \mathrm{~kg}$ of plutonium. To facilitate binning of the 3013 containers, the excess material has been placed into categories (Table 1.5) based on the type of processing the oxide will receive. The material considered for packaging into 3013 containers does not include oxide from weapons-component reprocessing.

Oxide from Dry Operations consists of oxide with nominally greater than $70 \mathrm{wt} \%$ plutonium and will receive no further chemical reprocessing. The oxide will be stabilized per 3013 requirements, packaged into 3013 containers, and characterized by prompt gamma analysis. Oxide in this category originated from several processes, including pyrochemical processing, metal oxidation, mixed oxides, and higher-purity oxide from liquid processing. Items containing chloride and nominally $20-70 \mathrm{wt} \%$ plutonium will undergo chloride reprocessing, which includes hydrochloric acid dissolution, solvent extraction, oxalate precipitation and calcination. The resulting oxide will be characterized by chemical analysis and is expected to contain greater than $85 \mathrm{wt} \%$ plutonium. Oxide/oxide-like materials containing $40-70 \mathrm{wt} \%$ plutonium (without chloride contamination) will undergo nitrate reprocessing using nitric acid $\left(\mathrm{HNO}_{3} / \mathrm{HF}\right)$ 
Table 1.5 LANL Material Categories

\begin{tabular}{|l|c|c|}
\hline Process & $\mathrm{Pu}(\mathrm{Kg})$ & $\begin{array}{c}\text { Number of 3013 } \\
\text { Containers }\end{array}$ \\
\hline Dry Operations (from vault, no reprocessing) & 306 & 102 \\
\hline Chloride/Nitrate Processing & 339 & 113 \\
\hline Total & 645 & 215 \\
\hline
\end{tabular}

dissolution, ion exchange, and oxalate precipitation followed by calcination. The resulting oxide will also be characterized by chemical analysis and is expected to contain greater than $85 \mathrm{wt} \%$ plutonium.

The initial projection of containers from Dry Operations (no recovery step) consists of 102 containers with oxide greater than $70 \mathrm{wt} \%$ plutonium. Based on process knowledge, an estimated 15 of these containers will be categorized as Innocuous, 57 containers as Pressure, and 30 containers as Pressure and Corrosion.

Of the 113 containers reprocessed using the chloride or nitrate process, all should have a plutonium content greater than $85 \mathrm{wt} \%$. However, historical information on high-purity oxides suggests that 28 of these containers will have moisture content above the cutoff levels to be considered Innocuous and will be placed in the Pressure bin. The remaining 85 containers will go into the Innocuous bin. If oxides from chloride processing are found to contain residual chloride, all of the containers from this process will be placed in the Pressure and Corrosion bin.

The binning decision tree for LANL containers is shown in Figure 1.7. These binning results are incomplete at this time and will be revised when more accurate data become available. The best estimate of the total population in each of the three bins is 100 containers in the Innocuous bin, 30 containers in the Pressure and Corrosion bin, and 85 containers in the Pressure bin.

\subsection{Binning Summary}

Binning results for all 3013 containers are shown in the summary decision tree (Figure 1.2) and summarized in Table 1.6. The results from a cursory evaluation of containers yet to be packaged are also included in this table to provide a preliminary picture of the distribution of the total 3013 containers expected to be in storage. It should be noted that the accuracy of the binning for containers not yet packaged varies with the quality of the information provided by the sites. If the final number of unpackaged containers varies from the estimated number, revisions to the sample specification defined in Section 2.0 may be required. Thus, a rough picture of the magnitude of the field surveillance program can be provided for planning purposes. Also included are the binning decision trees for each site (Figures 1.3 through 1.7). These decision trees reflect the data summarized in Table 1.6 and illustrate the inductive logic of the binning process. 
Table 1.6 Binning of All DOE 3013-Type Containers

\begin{tabular}{|l|c|c|c|c|}
\hline \multicolumn{1}{|c|}{ Site } & Innocuous & Pressure & $\begin{array}{c}\text { Pressure } \\
\text { And } \\
\text { Corrosion }\end{array}$ & Total \\
\hline $\begin{array}{l}\text { Rocky Flats } \\
\text { Packaged }\end{array}$ & $808(+22)^{*}$ & $721(+115)$ & $359(-144)$ & $1888(-7) \dagger$ \\
\hline $\begin{array}{l}\text { Hanford } \\
\text { Packaged }\end{array}$ & $921(-23)$ & $746(+160)$ & $590(-137)$ & 2257 \\
Unpackaged & $0(-9)$ & $0(-9)$ & 0 & $0(-18)$ \\
\hline $\begin{array}{l}\text { LLNL } \\
\text { Packaged }\end{array}$ & $9(+2)$ & $9(+4)$ & $56(-6)$ & $74(0)$ \\
Unpackaged & 0 & 0 & $61(0)$ & $61(0)$ \\
\hline $\begin{array}{l}\text { SRS } \\
\text { Packaged }\end{array}$ & $746(-3)$ & $103(+103)$ & $71(+71)$ & 920 \\
Unpackaged & $0(-41)$ & $0(-150)$ & $0(-100)$ & $0(-120)$ \\
\hline $\begin{array}{l}\text { LANL } \\
\text { Packaged }\end{array}$ & 12 & 18 & 2 & 32 \\
Unpackaged & $88(-68)$ & $67(+60)$ & $28(-119)$ & $183(-127)$ \\
\hline Total & $2584(-120)$ & $1664(+283)$ & $1167(-435)$ & $5415(-272)$ \\
\hline
\end{tabular}

$*$ Numbers in ( ) indicate the change between FY 2005 and FY 2006.

$\dagger$ Rocky Flats sent LANL 7 metal containers that were removed from the surveillance program. 


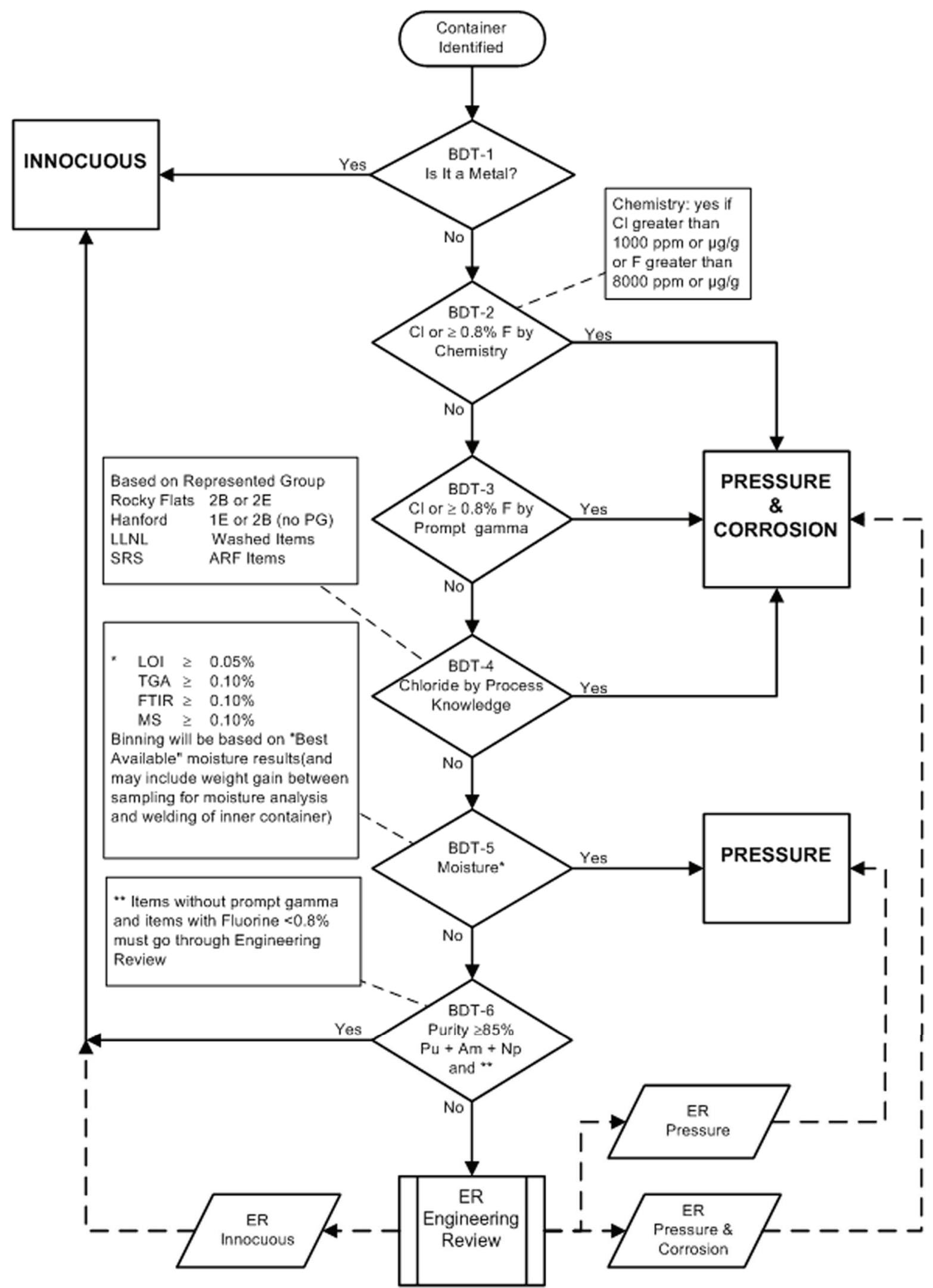

Figure 1.1. Generic decision tree for binning 3013 items for field surveillance. 


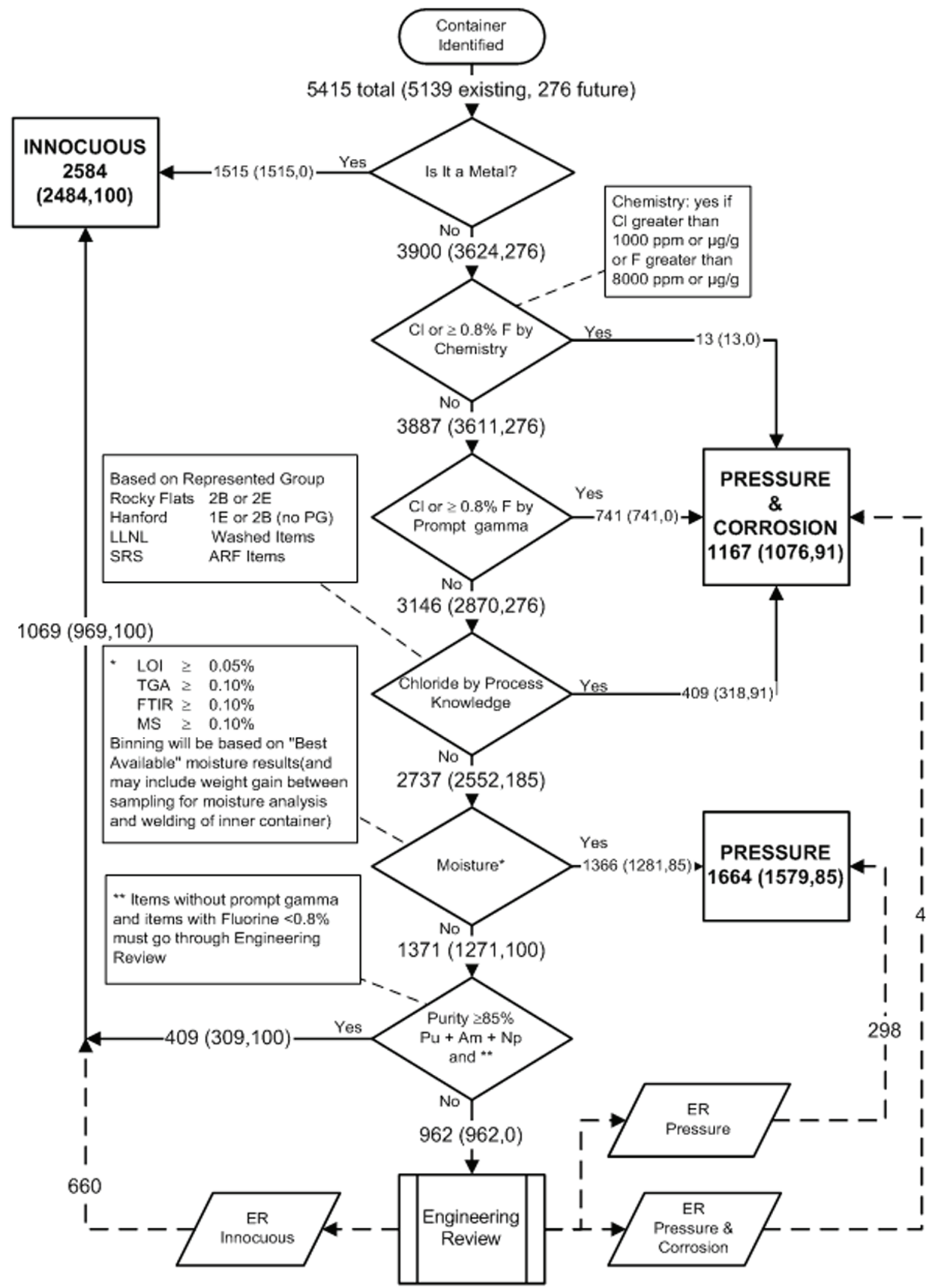

Figure 1.2. Composite binning decision tree for all 3013 surveillance items. 


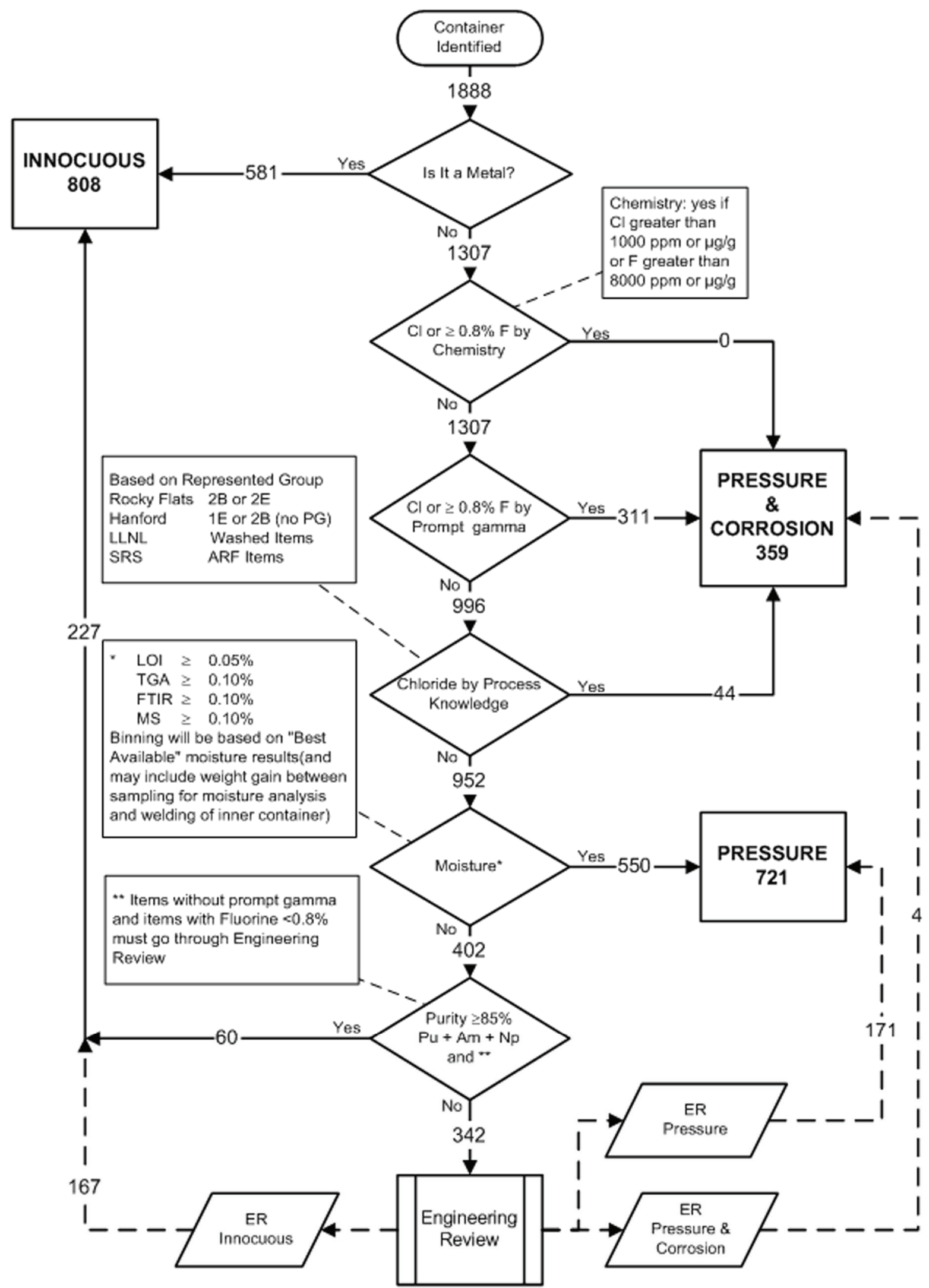

Figure 1.3. Rocky Flats binning decision tree. 


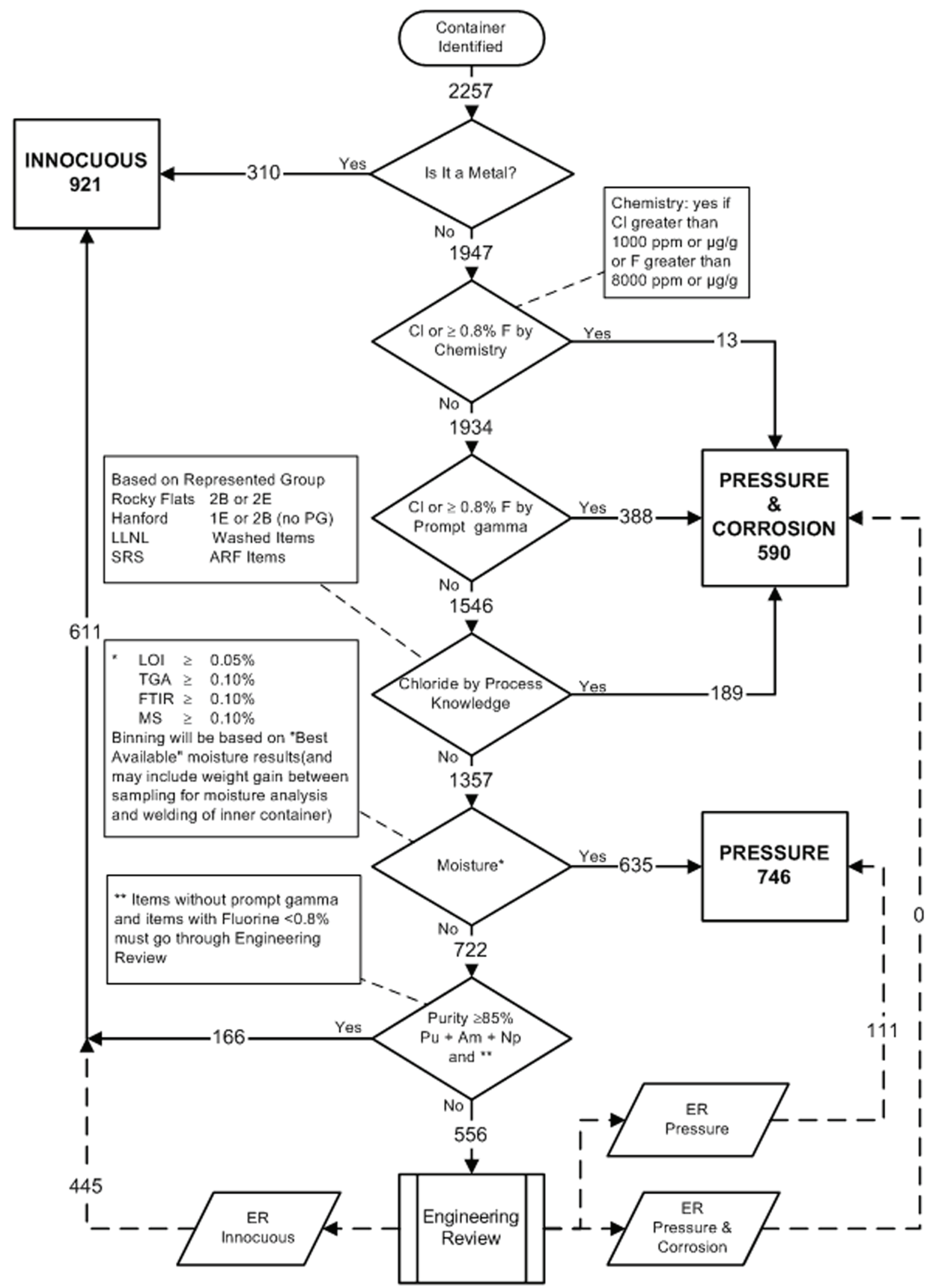

Figure 1.4. Hanford binning decision tree. 


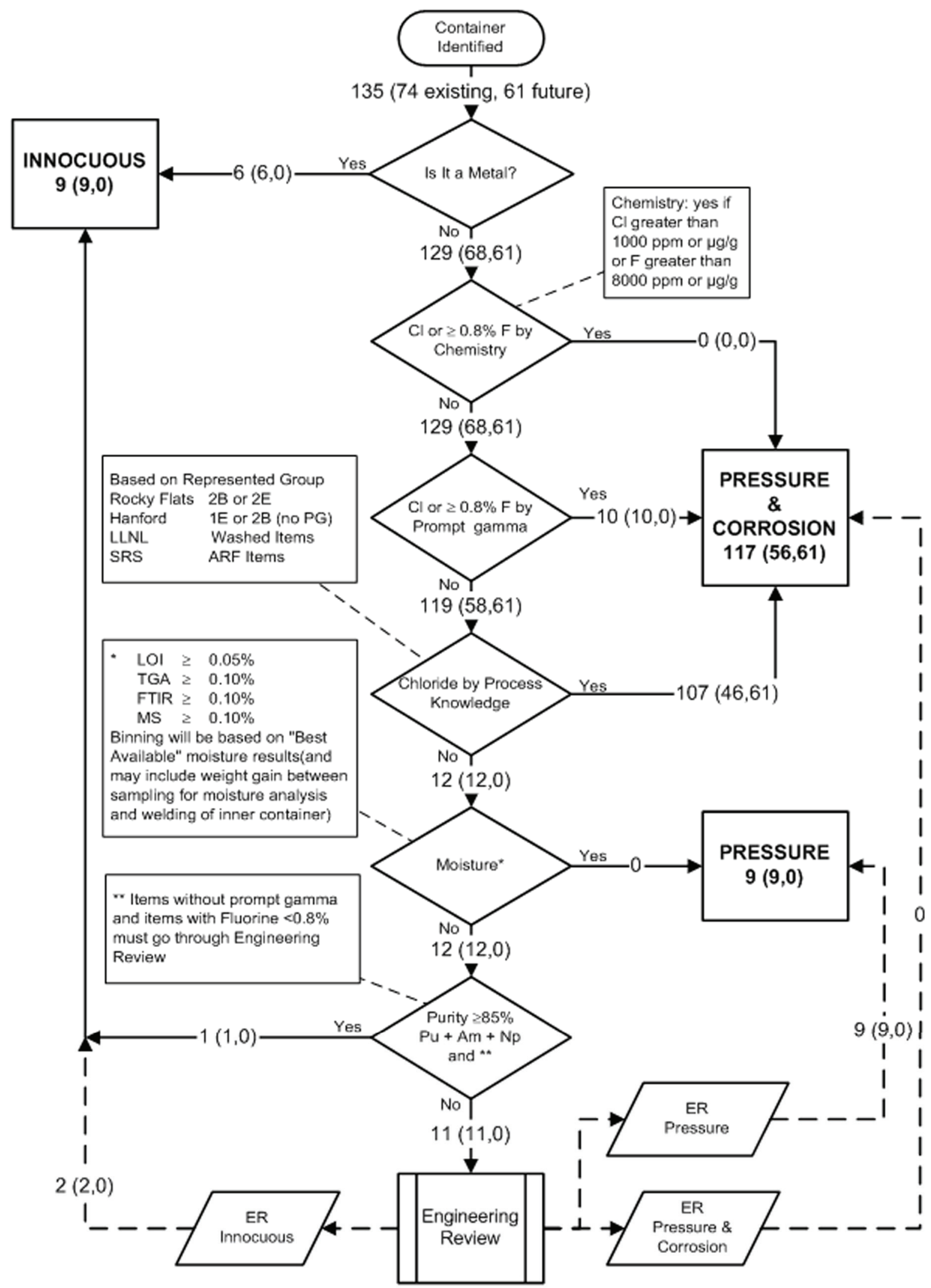

Figure 1.5. LLNL binning decision tree. 


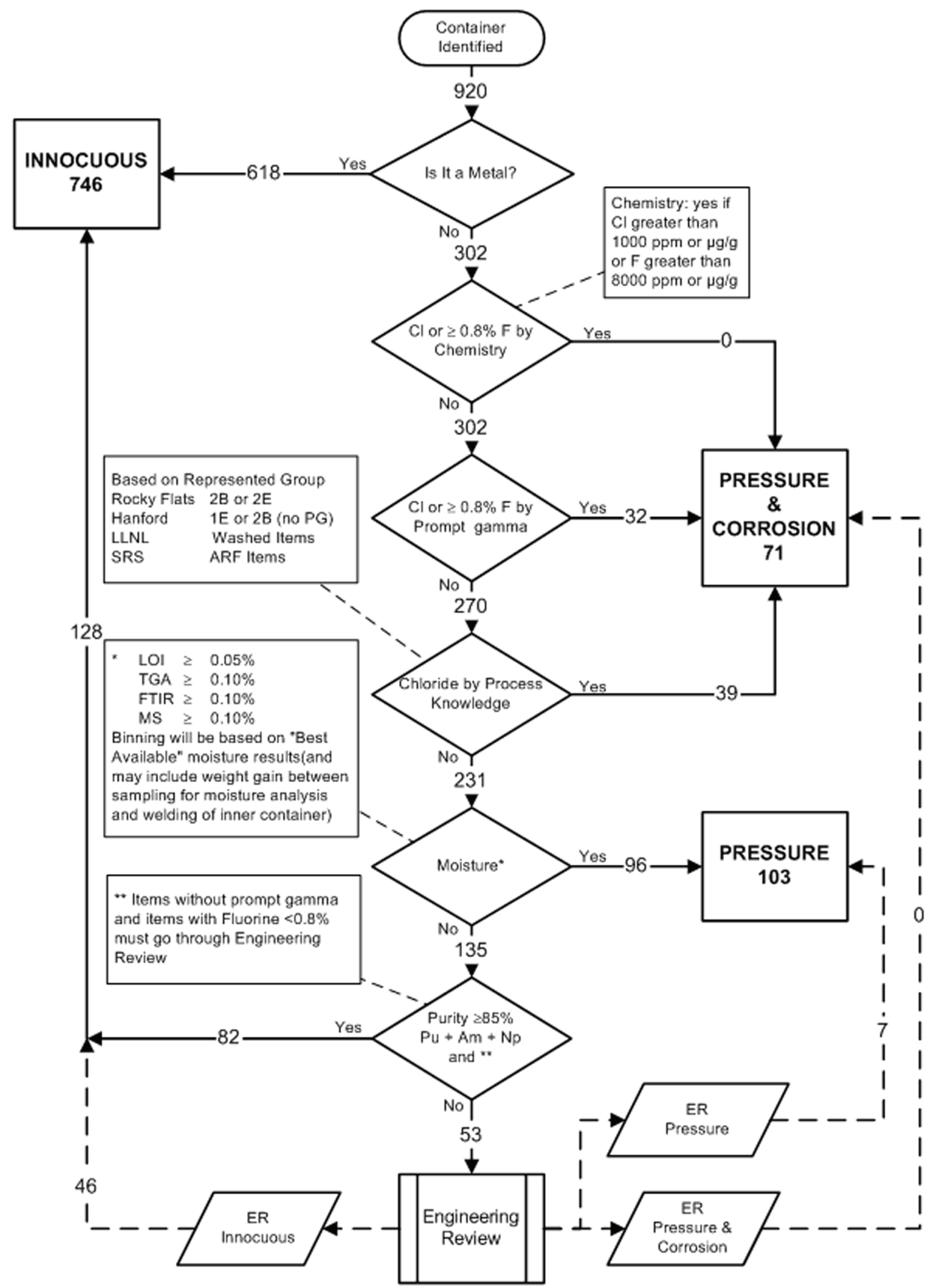

Figure 1.6. SRS binning decision tree. 


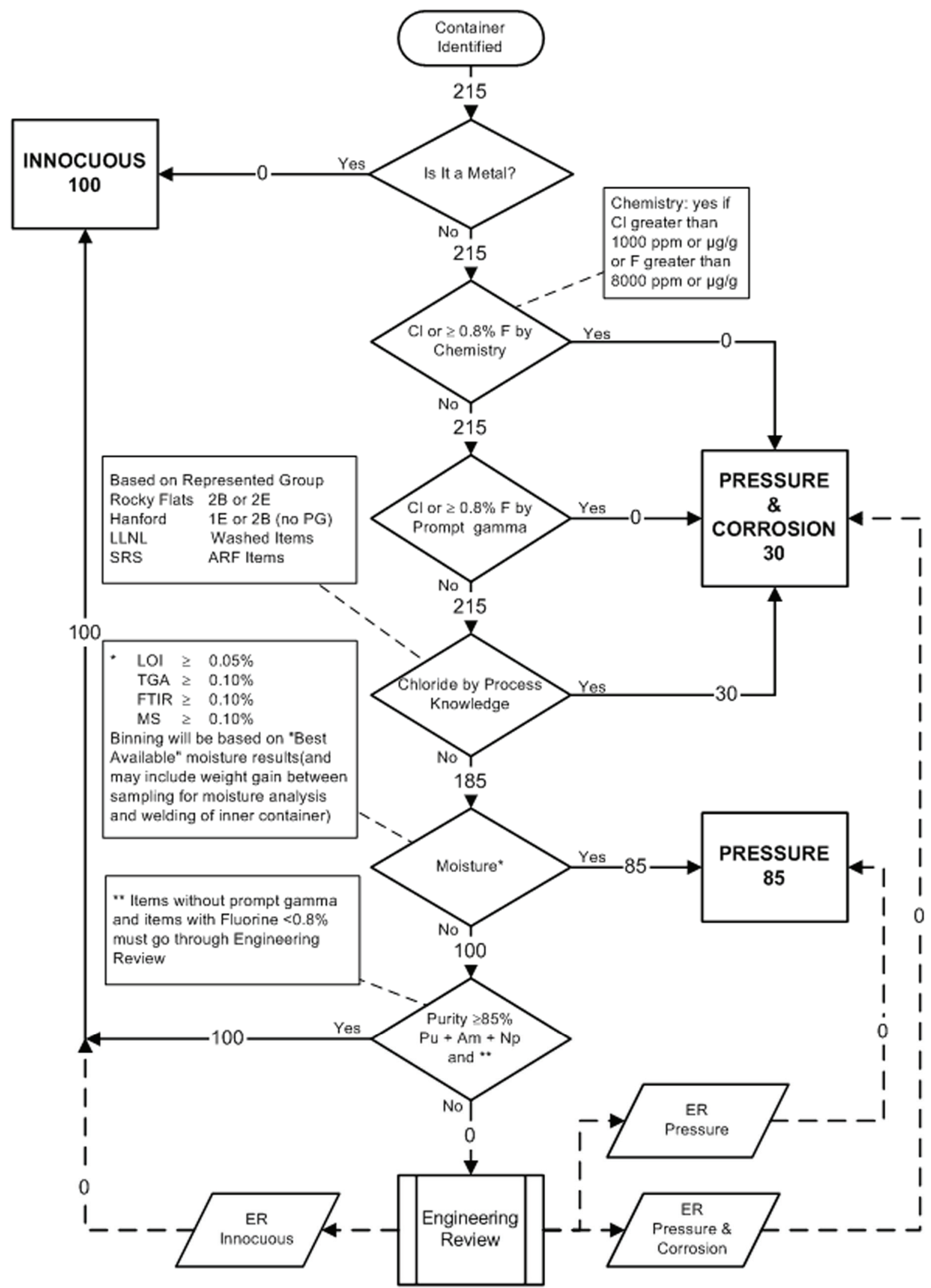

Figure 1.7. LANL binning decision tree. 


\subsection{Surveillance Sampling_-The Statistical Sample}

\subsection{Introduction}

The requirement of $99.9 \%$ probability of observing at least one of the worst $5 \%$ (denoted as $99.9 \% / 5 \%$ ) is used to guide the statistical sampling process for the Pressure and Corrosion and Pressure bins. The hypergeometric distribution is used to determine the number of containers needed to meet this requirement. ${ }^{22}$

Using this criterion does not necessarily mean that containers have significant degradation. It simply means that (in theory) at the end of 50 years, all containers could be evaluated and ranked for their degree of degradation (higher rank, higher degradation). This ranking could take place even if there was very little, if any, degradation, and even if the containers varied little in terms of degradation. The $5 \%$ with the highest scores would be the "worst" $5 \%$. It is not necessary to actually rank the containers to implement this statistical approach.

The main attribute of this approach is that it requires no assumptions about which container or group of containers are the "worst." The random sampling alone provides the specified degree of confidence (e.g., 99.9\%) that at least one of the containers from the worst $5 \%$ will be observed. It should be noted that an important assumption of this approach is that a container has a valid assessment of its ultimate (50 years) degradation when it is examined.

The statistical calculations for the sample size are generally independent of population size if the population has over 500 items. However, the number of items in the worst $5 \%$ clearly depends on the population size.

The statistical sample for the Innocuous bin is based on the assumption that these containers will show no degradation; therefore, there will be almost no variability in the pressurization and corrosion evaluations. A random sample of 10 containers is selected from this bin to test the assumptions of very little variability and no degradation.

The statistical sample for the Pressure and Corrosion bin and Pressure bin gives a high level of confidence that at least one of the worst $5 \%$ of all containers in a bin will be observed in the samples selected. These samples also provide data for predicting the behavior of pressurization and corrosion for the entire population. However, the question remains, what if there are just a few "problematic containers" that are very different than the rest of the containers in the population? To address this issue, the statistical samples will be augmented with judgmental sampling. The judgmental sampling will use engineering judgment, results of the shelf-life studies, results of the statistical sampling, and other sources of information to target containers that could have the greatest potential for degradation. The combined approach of statistical and judgmental sampling is a powerful, cost-effective tool for ensuring the safe storage of the 3013 containers. The details of the judgmental sampling are described in Section 3 of this report. 


\subsection{Statistical Sample Selection}

\subsubsection{Sample Sizes}

Based on the number of containers in the Pressure and Corrosion and Pressure bins given in Section 1, Table 1.6, sample sizes of 128 containers for the Pressure and Corrosion bin and 130 containers for the Pressure bin meet the $99.9 \% / 5 \%$ criterion. However, the decision was made to evaluate 131 containers in the random sample for the Pressure and Corrosion bin. ${ }^{*}$

The random sample was allocated proportionally to each packaging site. For example, for Hanford, the number of containers in the Pressure and Corrosion bin sample was

590 (Hanford containers)/1,167(total containers in bin) $\mathrm{x} 131$ (total samples in bin) $=66$ (Hanford containers in the sample)

Table 2.1 gives the distribution of sample sizes across the various sites.

The Pressure and Innocuous random NDE sampling campaigns began in 2005 and are scheduled to be completed in $2009 .{ }^{6}$ At this point, the results will be evaluated to determine future surveillance quantity and frequency. The containers must be at least three years old at the time of evaluation. Therefore, containers considered for the Pressure and Innocuous samples must have been packaged as of June 2006.

Table 2.1. Distribution of Sample Sizes in the Pressure and Corrosion and Pressure Bins Across Sites

\begin{tabular}{|l|c|c|}
\hline & Pressure and Corrosion & Pressure \\
\hline Hanford & 66 & 61 \\
\hline LLNL & 13 & 1 \\
\hline Rocky Flats & 40 & 59 \\
\hline SRS & 8 & 8 \\
\hline LANL & 4 & 1 \\
\hline TOTAL & 131 & 130 \\
\hline
\end{tabular}

\subsubsection{Sample Selection}

In all cases, items to be included in the random samples were selected using the "Random Sample," option in the statistical software, S-Plus. ${ }^{23}$ However, as described below, this was done differently for the three bins.

\subsubsection{Pressure and Corrosion Bin}

For the Pressure and Corrosion bin, the S-Plus "Random Sample" option was used to generate $n$ numbers (sample size) ranging from one to the total number of packaged containers in the binsite (e.g., 66 random numbers ranging from one to 590 for Pressure and Corrosion-Hanford). These random numbers were associated with container item identification numbers (ID) by

\footnotetext{
* The FY 2005 binning specification had more items in the Pressure and Corrosion bin, and the required sample size for that bin specification was 131. The decision was made to keep this number of items in the sample.
} 
mapping them to the order that the container was generated for that bin at that packaging site. Appendix A, Table A-1 gives the container ID, site, current (FY 2006) bin assignment, reason for bin assignment as noted in the decision trees (FY 2006 Sub Bin) and inner can date and the fiscal year in which DE should be performed for the statistical samples for all of the packaging sites except for LANL and for 7 containers from the 61 that have not yet been packaged at LLNL.

\subsubsection{Pressure Bin}

For SRS, LLNL, and LANL the sample selection was done in the same way as the Pressure and Corrosion sample selection. For Rocky Flats and Hanford, the Pressure sample selection was done differently. As noted before, there had been a previous binning of containers and a previous random sample for each bin in FY 2005. ${ }^{1-3}$ The main difference between the FY 2005 bin assignments and the new FY 2006 bin assignments is that some containers moved from Pressure and Corrosion to the Pressure bin. For Rocky Flats and Hanford, the FY 2005 and FY 2006 sample containers had been evaluated or were in the process of being evaluated. ${ }^{\dagger}$ To retain as much of the FY 2005 sample as possible and maintain the $99.9 \% / 5 \%$ criterion, the following approach was taken for the Pressure bin.

The bin-site sample size was proportionally allocated between the FY 2005 and FY 2006 Pressure bin containers that remained after the FY 2006 rebinning and the new bin containers for each packaging site. This resulted in 14 containers in the sample from the new containers for Pressure-Hanford and 13 for Pressure-Rocky Flats (Table 2.2). The sample for the new bin containers was selected from the new containers as described for the Pressure and Corrosion bin. The sample for the old bin containers (47 for Hanford and 46 for Rocky Flats) was selected randomly from the FY 2005 sample. Appendix A, Table A-2 lists the information for Pressure bin containers as well as the fiscal year in which the NDE should be performed.

Table 2.2.Pressure Bin Sample Selection for Hanford and Rocky Flats

\begin{tabular}{|l|c|c|c|c|c|c|}
\hline & Containers & $\begin{array}{c}\text { New } \\
\text { Containers }\end{array}$ & $\begin{array}{c}\text { Proportion } \\
\text { New } \\
\text { Containers }\end{array}$ & $\begin{array}{c}n \\
\text { (sample } \\
\text { size) }\end{array}$ & $\begin{array}{c}n \text { from } \\
\text { New } \\
\text { Containers }\end{array}$ & $\begin{array}{c}n \text { from } \\
2005 \\
\text { sample }\end{array}$ \\
\hline Hanford & 746 & 168 & .225 & 61 & 14 & 47 \\
\hline Rocky Flats & 721 & 154 & .214 & 59 & 13 & 46 \\
\hline
\end{tabular}

\subsubsection{Innocuous Bin}

The material in the Innocuous bin containers is either plutonium metal or relatively pure plutonium oxide with low water content. It is not credible for plutonium metal packaged per the 3013 standard to generate pressure except for the relatively low pressure of helium generated from alpha decay. ${ }^{14}$ In addition, failure of the container from corrosion or metal-to-metal interaction between the plutonium metal and the storage container is also not credible. ${ }^{15}$ For these reasons, the MIS Working Group concluded that the metals present no risk of

\footnotetext{
${ }^{\dagger}$ Note: None of the Pressure and Corrosion bin containers from the old sample specification had been evaluated destructively; therefore, it was decided to select all new containers for the Pressure and Corrosion bin.
} 
pressurization or corrosion, and that the surveillance sample for the innocuous bin is focused on oxide containers only. This assumption will be evaluated at LANL when a metal item packaged at Rocky Flats in a 3013 container is opened for programmatic use.

Ten oxide containers are to be evaluated for the Innocuous bin. These ten containers are selected randomly from the oxide population using stratified random sampling. The Innocuous bin is divided into three strata for sampling purposes; oxides classified as innocuous based on the decision tree with no need for engineering review (Oxides-No ER), oxides classified as innocuous using engineering review but not containing fluoride above 1,000 ppm (Oxides-ERNo F) and those with fluoride above $1,000 \mathrm{ppm}$ but below 8,000 ppm (Oxides-ER- F). Two containers are selected randomly from the fluoride stratum, and the other eight are proportionally allocated to the other strata and selected randomly from these strata. Table 2.3 shows the distribution of the number of containers and sample sizes. The containers selected for the Innocuous sample are also given in Appendix A, Table A-3, which lists the information for Innocuous containers as well as the fiscal year in which the NDE should be performed.

Table 2.3. Distribution of Numbers of Containers and Numbers of Sample Containers in the Innocuous Bin

\begin{tabular}{|l|c|c|c|c|c|c|}
\hline Site & \multicolumn{2}{|c|}{ Oxides - No ER } & \multicolumn{2}{c|}{ Oxides - ER - No F } & \multicolumn{2}{c|}{ Oxides-ER - F } \\
\hline & $\begin{array}{c}\text { \# of } \\
\text { Containers } \\
\text { in stratum }\end{array}$ & $\begin{array}{c}\text { \# of } \\
\text { Containers } \\
\text { in sample }\end{array}$ & $\begin{array}{c}\text { \# of } \\
\text { Containers } \\
\text { in stratum }\end{array}$ & $\begin{array}{c}\text { \# of } \\
\text { Containers } \\
\text { in sample }\end{array}$ & $\begin{array}{c}\text { \# of } \\
\text { Containers } \\
\text { in stratum }\end{array}$ & $\begin{array}{c}\text { \# of } \\
\text { Containers } \\
\text { in sample }\end{array}$ \\
\hline Hanford & 166 & 1 & 438 & 3 & 7 & - \\
\hline LLNL & 1 & - & 2 & - & 0 & - \\
\hline Rocky Flats & 60 & 1 & 145 & 1 & 22 & 2 \\
\hline SRS & 82 & 1 & 42 & 1 & 4 & - \\
\hline LANL & 0 & - & 12 & - & - & - \\
\hline Total & 309 & 3 & 639 & 5 & 33 & 2 \\
\hline
\end{tabular}

ER - Engineering Review for classification into Innocuous Bin. 


\subsection{Selection of 3013 Containers for Field Surveillance-Statistical and Judgmental Samples}

\subsection{Introduction}

Using the criterion described in Sections 1 and 2, 131 containers were needed from the Pressure and Corrosion bin and 130 containers from the Pressure bin. The 131 containers from the Pressure and Corrosion bin will be destructively evaluated over a ten-year period beginning in 2007. They will have NDE and DE, with some NDE beginning in Fiscal Year (FY) 2005. The 130 containers from the Pressure bin will have NDE, and the evaluations are concentrated over a five-year period that began in FY 2005. In addition, two containers from the Pressure bin will be selected in years FY 2007, FY 2008, and FY 2009 to have DE performed to validate the assumption that there is no corrosion occurring in these containers.

Packaging is ongoing, and a portion of the total population currently does not exist. In the Pressure and Corrosion bin, 1,076 of the projected 1,167 containers have been packaged. In the Pressure bin, 1,579 of the projected 1,664 containers have been packaged. Of the 131 containers in the statistical sample for the Pressure and Corrosion bin, 120 are packaged, and of the 130 containers in the Pressure bin sample, 129 are packaged.

The statistical sample is augmented with judgmental sampling to provide a powerful, costeffective tool for ensuring the safe storage of the 3013 containers. The judgmental sampling uses engineering judgment, results of the shelf-life studies, comparison of the statistical sample to the population, packaging and stabilization data and field surveillance results (when available) to identify additional containers for surveillance. The judgmental sample targets containers with the greatest potential for degradation and data gaps, if any, in the statistical sample.

\subsection{NDE Samples for FY 2005}

The following discussion presents the rationale that was used for the selection of containers for NDE in FY 2005. The FY 2005 NDE sample consists of a subset of the FY 2005 statistical sample and a judgmental sample. The containers in the judgmental sample were believed, on the basis of current data at the time of selection, to have the highest potential for pressurization and/or corrosion.

\subsubsection{Summary of FY 2005 Container Selection}

Table 3.1 lists the 52 containers selected for NDE in FY 2005, which met the minimum requirements of the ISP. Hanford evaluated 23 containers, SRS evaluated 27 containers (originally packaged at Rocky Flats), and LLNL evaluated two containers. Ten additional containers were examined by Hanford in FY 2005 (Table 3.2).

It was originally believed that a few of the Hanford containers listed in Table 3.1 could not be accurately radiographed with the existing radiography system and software because they were what the facility calls "dead-zone-affected." ${ }^{24-25}$ The facility requested that surveillance of these containers be deferred until software fixes were implemented. However, SRS expedited the development of a new software version that allowed multiple angle imaging of the container, allowing a best view to be selected. This version was successfully used on a test basis for these 
Table 3.1. 3013 Containers Selected for NDE Surveillance in FY 2005

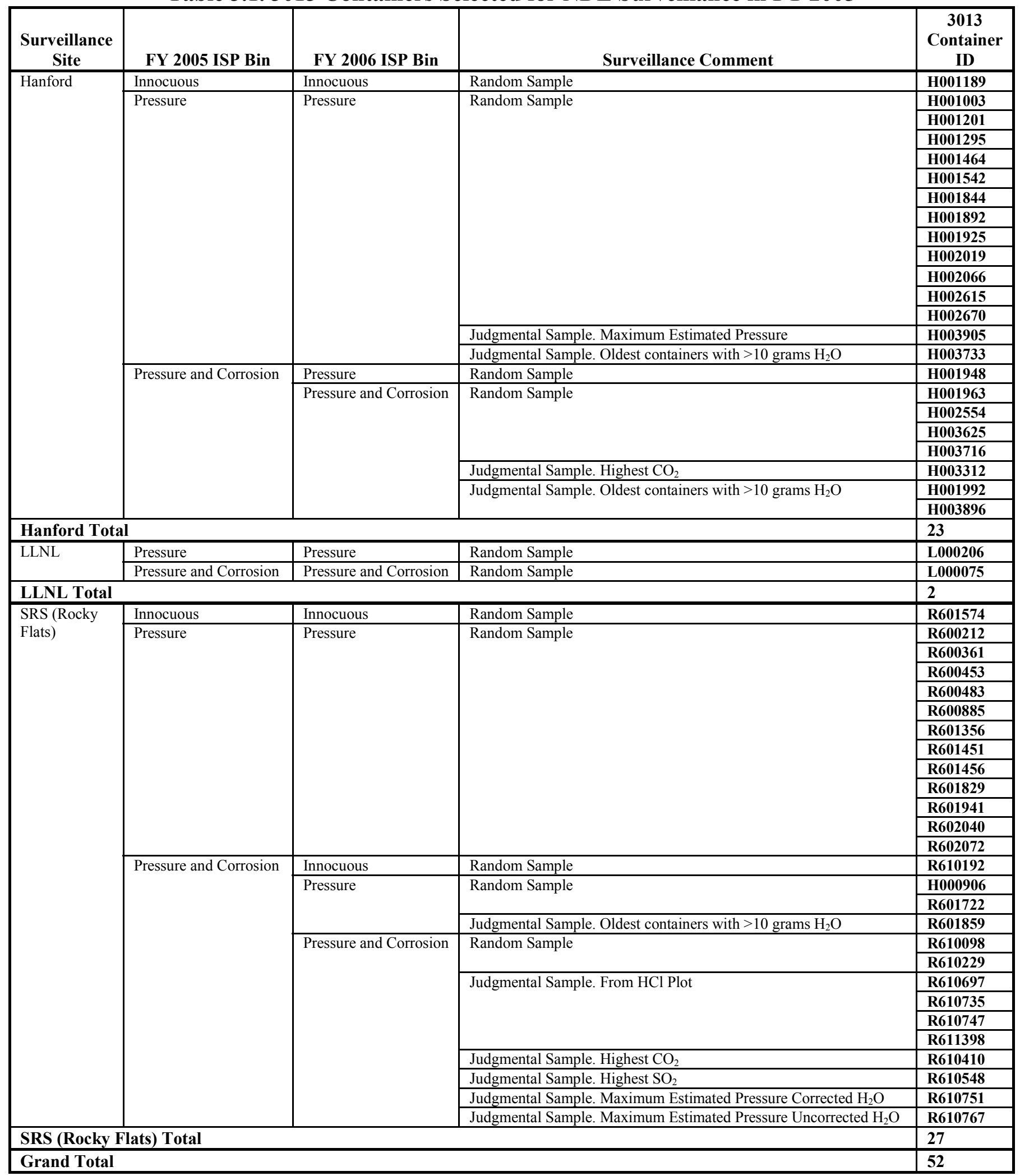


Table 3.2.Additional Hanford NDE samples in FY 2005

\begin{tabular}{|c|c|c|c|}
\hline $\begin{array}{l}\text { FY } 2005 \text { ISP } \\
\text { Bin }\end{array}$ & $\begin{array}{l}\text { FY } 2006 \text { ISP } \\
\text { Bin }\end{array}$ & Comment & $\begin{array}{c}3013 \\
\text { Container } \\
\text { ID }\end{array}$ \\
\hline \multirow[t]{10}{*}{$\begin{array}{l}\text { Pressure and } \\
\text { Corrosion }\end{array}$} & \multirow[t]{2}{*}{ Pressure } & $\begin{array}{l}\text { From precipitation of Misc. Lab Solution/RL } \\
\text { Request }\end{array}$ & H001181 \\
\hline & & $\begin{array}{l}\text { PFP Scrap Oxide/Highest Theoretical Pressure by } \\
\text { TGA }\end{array}$ & H002444 \\
\hline & \multirow{8}{*}{$\begin{array}{l}\text { Pressure and } \\
\text { Corrosion }\end{array}$} & \multirow[t]{2}{*}{ Rocky Flats Oxide with Chloride (ARF) } & H002565 \\
\hline & & & H002715 \\
\hline & & ARF, Highest water by Mass Spec & H003710 \\
\hline & & ARF, Second Highest water by Mass Spec & H003737 \\
\hline & & $\begin{array}{l}\text { ARF/Bad PG/Container sampled for MOX } \\
\text { program }\end{array}$ & H004075 \\
\hline & & \multirow[t]{2}{*}{ ARF with High water } & H002557 \\
\hline & & & H003392 \\
\hline & & $\begin{array}{l}\text { From precipitation of Misc. Lab Solution/Highest } \\
\text { Water by Mass Spec }\end{array}$ & H001236 \\
\hline
\end{tabular}

affected samples in FY05, preserving the integrity of the random sample. ${ }^{26}$ This new version has been placed into service at Hanford, allowing any dead-zone-affected container to be radiographed.

\subsubsection{Process for Selecting Containers for FY 2005}

The containers in the statistical sample consisted of 25 containers from the Pressure bin random sample and ten containers from the Pressure and Corrosion bin random sample. The selection of containers from the random sample for NDE in FY 2005 was made by sorting containers from each site and each bin by age of the inner can weld date. Those older than the median age for a bin and a generation site were identified as possible candidates for selection. For each of these groups, the specified number of containers was selected randomly.

The process for selecting containers for the judgmental sample in FY 2005 was twofold. The first step was a detailed comparison of the 3013 population to the 225 existing containers in the statistical sample to determine if there were any important properties of the population that are not represented adequately in the sample. A detailed analysis of the FY 2005 sample is documented in LA-UR-05-2193. ${ }^{3}$ No significant gaps in sample coverage were identified in the sample versus the total population.

The second step consisted of a specification of those properties considered to be most important in terms of potential container pressurization and/or corrosion. Both of these steps involved considerable discussion during conference calls and meetings with the Materials Identification and Surveillance (MIS) Working Group and others. At the completion of the analyses and ensuing discussions, the MIS Working Group recommended containers for surveillance to the ISP Steering Committee, and the ISP Steering Committee approved the recommended NDE containers for FY $2005 .^{27}$ 


\subsubsection{Selection of Containers Based on Engineering Judgment}

Because no major data gaps were identified when the FY 2005 statistical sample was compared

to the population, ${ }^{3}$ the MIS working group decided that containers for judgmental sampling should be based on a worst-case analysis. That is, those containers with the greatest potential for pressurization and/or corrosion, based on current information at the time of selection, should be considered for NDE in FY 2005. Four criteria were used to identify worst-case candidates: high reported water content, $\mathrm{HCl}$ generation during moisture measurement, detection of high levels of $\mathrm{SO}_{2}$ or $\mathrm{CO}_{2}$ during moisture measurement, and those containers with the maximum estimated pressure generation.

\subsubsection{Water Content}

For pressurization and/or corrosion to occur, water must be present. The 3013 Standard allows a maximum of $0.5 \mathrm{wt} \%$ of adsorbed water in a container. Using a criterion of the highest weight percent water was not sufficient to define the worst case for water content without taking into account the net weight of the container. Few containers had measured water content greater than ten grams. The four oldest containers with water content of around 10 grams or more were included in the judgmental sample (Table 3.1). The container certification moisture analysis was used for FY 2005 binning and the determination of grams of water for this analysis. As noted previously, binning criteria were changed for FY 2006, to use the best available moisture result. This resulted in many containers moving from the Pressure bin to the Innocuous bin.

\subsubsection{HCl Generation}

TGA-FTIR data that were collected at Rocky Flats for poststabilization verification of moisture content also showed $\mathrm{HCl}$ in the purge gas downstream of the sample during heating of some container samples. These observations were first documented in LA-UR-04-0654 ${ }^{20}$ The detection of $\mathrm{HCl}$ during these analyses is of interest because (1) it suggests a thermal mechanism for generation of a corrosive gas from stabilized material after packaging; (2) it may be a useful indicator of the presence of chlorine in stabilized material; and (3) it may reveal the presence of chemical forms of elemental chlorine and hydrogen that are of particular relevance in assessing corrosion risk.

Figure 3.1 shows the total detected $\mathrm{HCl}$ over the $225^{\circ} \mathrm{C}$ to $465^{\circ} \mathrm{C}$ TGA temperature range versus the detected $\mathrm{H}_{2} \mathrm{O}$ over the full TGA range for all TGA-FTIR samples of stabilized material. Four of the five containers showing an unambiguous $\mathrm{HCl}$ signal were chosen for the judgmental sample. These include two of the three containers that released the most $\mathrm{H}_{2} \mathrm{O}$ and two containers from among those that released the most $\mathrm{HCl}$ and that also released $\mathrm{H}_{2} \mathrm{O}$ exceeding $0.1 \mathrm{wt} \%$. The data points representing containers of interest for judgmental sampling are circled in Figure 3.1.

\subsubsection{3 $\mathrm{SO}_{2}$ and $\mathrm{CO}_{2}$ Generation}

TGA-FTIR data from Rocky Flats indicated a thermal release of $\mathrm{CO}_{2}$ and $\mathrm{SO}_{2}$ from some samples during poststabilization measurements. Calculations showed that $\mathrm{CO}_{2}$ and $\mathrm{SO}_{2}$ evolution can account for most of the mass loss in the subpopulation of Rocky Flats containers showing TGA mass loss greater than $0.3 \mathrm{wt} \%$. About $5 \%$ of the 600 samples analyzed fall into this subpopulation. Potential pressure generation is the principal concern with regard to these 


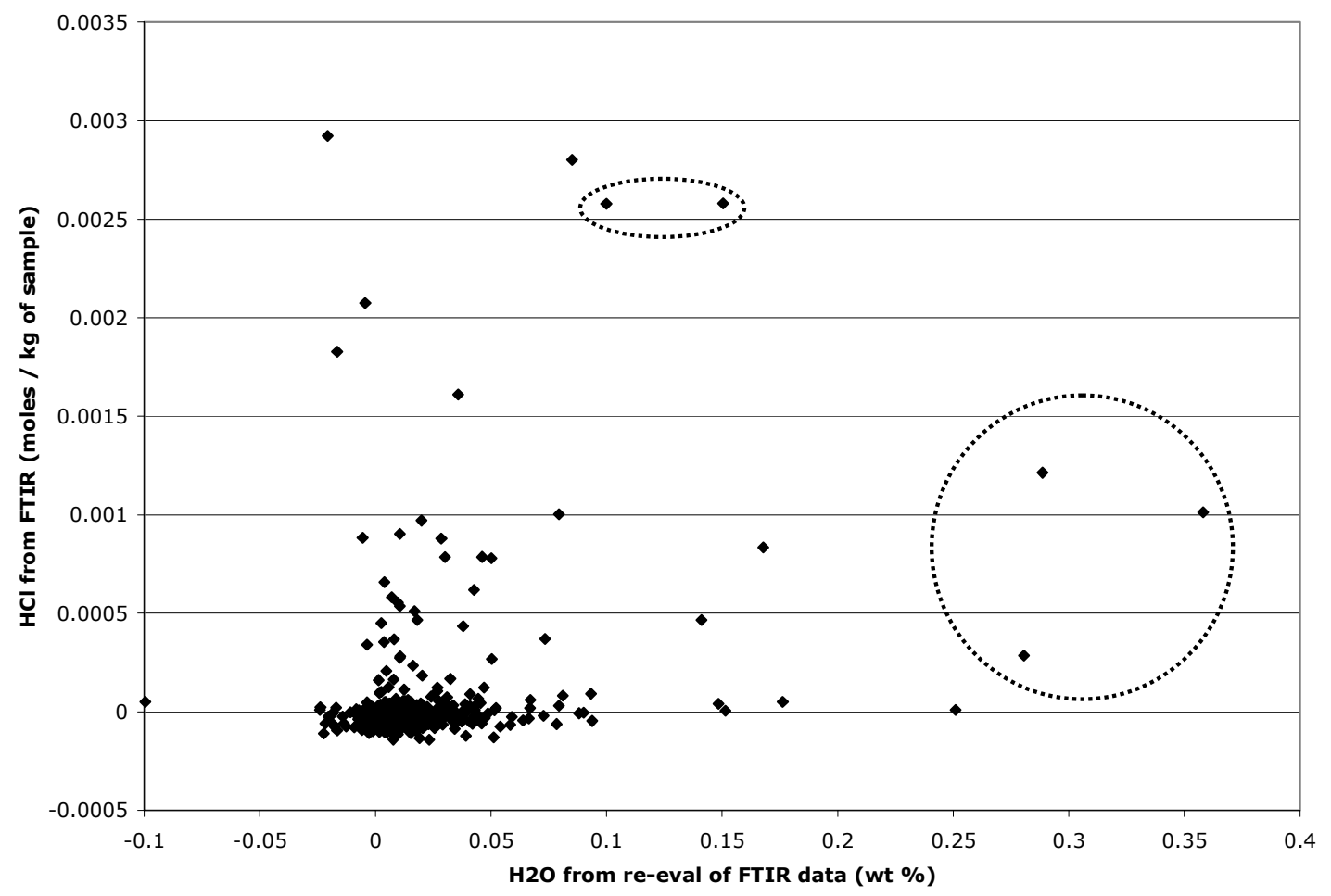

Figure 3.1. Detected $\mathrm{HCl}$ vs detected $\mathrm{H}_{2} \mathrm{O}$ from TGA-FTIR analysis of items originating at Rocky Flats. Items of interest as judgmental samples are circled.

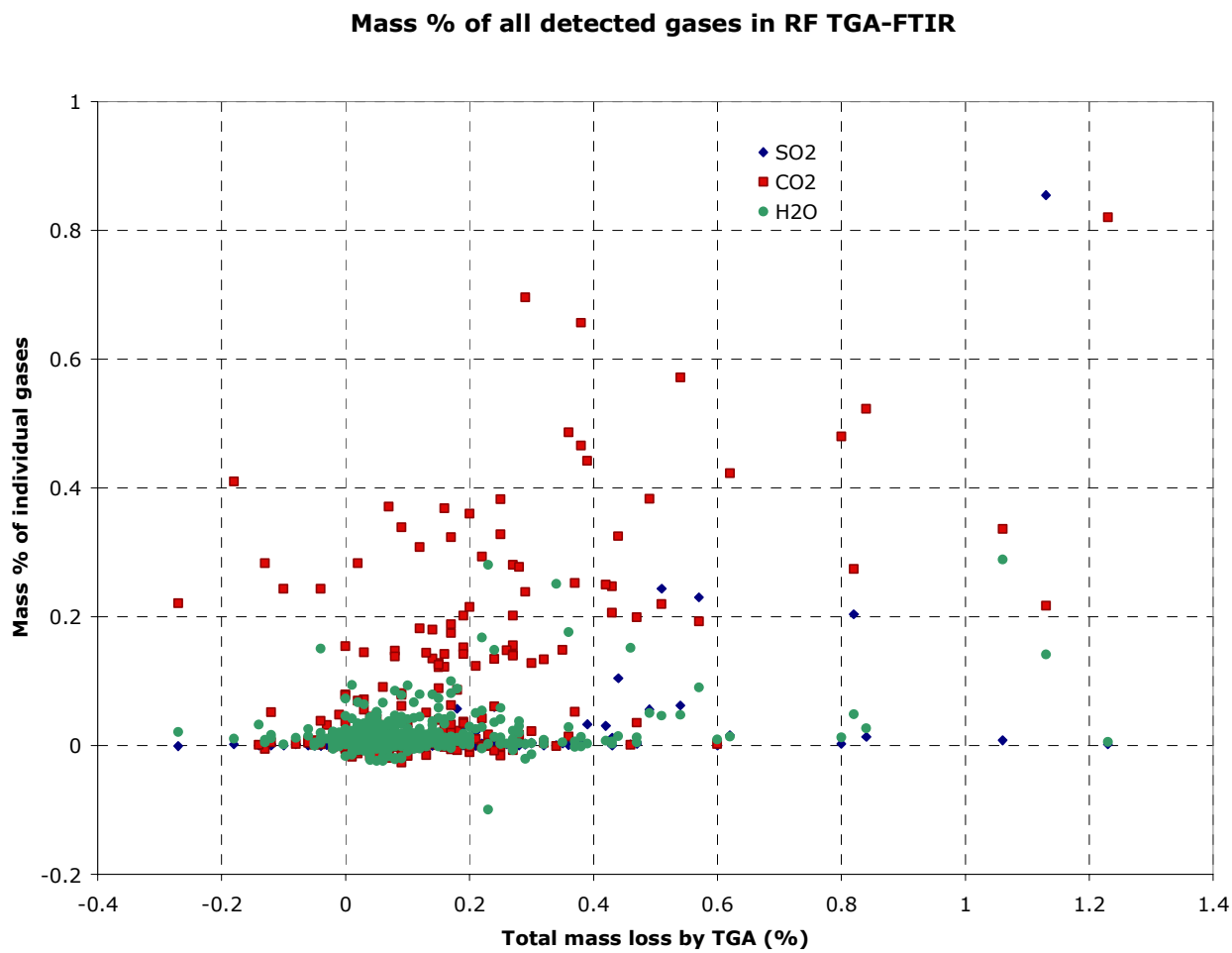

Figure 3.2. $\mathrm{CO}_{2}$ and $\mathrm{SO}_{2}$ generation during TGA-FTIR analysis of Rocky Flats items. 
gases. Neither gas was released in mole quantities exceeding the equivalent $\mathrm{H}_{2}$ possible from $0.5 \mathrm{wt} \% \mathrm{H}_{2} \mathrm{O}$. Furthermore, the temperatures at which these gases were generated in the TGA exceeded storage temperatures with the exception of minor quantities. These points are discussed with regard to $\mathrm{CO}_{2}$ in LA-UR-03-0811. ${ }^{28}$

Containers from Rocky Flats with the most $\mathrm{CO}_{2}$ and $\mathrm{SO}_{2}$ were selected for the judgmental sample. These containers are the two data points in the far top right in Figure 3.2. The Hanford container with the highest $\mathrm{CO}_{2}$ was selected for the judgmental sample on the basis of TGA-MS data where the sample showed low water content but greater than $1 \mathrm{wt} \%$ total weight loss determined to be $\mathrm{CO}_{2}$.

\subsubsection{Estimated Container Pressure Rise}

To identify containers with the greatest potential for pressurization, an algorithm was implemented to compute the pressure rise in containers known or suspected of containing chlorides. MIS items in the small-scale surveillance program that have chlorides present predominately generate hydrogen, but MIS items without chlorides generate other gases along

with hydrogen. ${ }^{19}$ Hydrogen is generated by radiolysis of water that is present in the material. Containers with the highest computed pressure rise were considered for engineering judgment.

Pressure rise was calculated using both the certification moisture value and the best available moisture value for each container. Container wattage, container weight, container volume, material assay (to calculate material density), and the worst-case G-value calculated from smallscale tests were also required for the calculation. Pressure rise was calculated using the date the inner container was welded as the starting time and February 1, 2005, as the date of the calculated pressure. Complete detail on the pressure rise calculation is included in LA-UR-05-2193. ${ }^{3}$

Based on the pressure rise calculations, two Rocky Flats containers were selected for judgmental sampling from the Pressure and Corrosion bin. One was based on the maximum uncorrectedmoisture (certification moisture value) pressure rise, and one was based on the maximum corrected-moisture (best moisture value) pressure rise. One container was selected for judgmental sampling from the Hanford-generated material Pressure bin based on the maximum uncorrected-moisture pressure rise. Table 3.1 shows the final selections for NDE based on pressure rise calculations.

\subsubsection{Recommendation of the MIS Working Group}

The MIS Working group provided a recommendation for the minimum number of containers on which each site should conduct NDE. This recommendation was based on comparisons of the random sample to the population, engineering review, and discussions among the MIS working group members, and was approved by the ISP Steering Committee. ${ }^{27}$ The list of containers in the ISP Steering Committee guidance was modified, based on logistical considerations at the surveillance sites and further discussions among the MIS working group members. Table 3.1 contains the final list of required NDE samples for FY 2005. 


\subsection{NDE Samples for FY 2006}

Sample selection for FY 2006 surveillance activities were identified in FY 2005 using the binning results from FY 2005. ${ }^{1}$ The FY 2006 NDE sample consists of a random selection of containers from the remaining containers in the random sample and a judgmental sample. Engineering judgment considerations used for the FY 2006 sample were similar to the criteria used for FY 2005.

\subsubsection{Summary of FY 2006 Container Selection}

Table 3.3 lists the 47 containers selected for NDE in FY 2006. Of these, 25 (based on FY 2005 binning) were from the Pressure random sample, and 11 were from the Pressure and Corrosion random sample; all were selected randomly. Of the remaining 11, nine were judgmental sample containers, and two were from the Innocuous bin random sample. The number of containers scheduled for evaluation by each site are as follows:

- Hanford-24 containers,

- SRS-22 containers (originally packaged at Rocky Flats), and

- LLNL-1 container.

These containers satisfy the FY06 selection criteria required by the ISP steering Committee for the DOE complex. ${ }^{29}$ All randomly selected containers were required to be at least three years old (from the inner can weld date) by the end of June 2006. This list has the minimum number of containers necessary to meet the requirements of the ISP. At least two additional Rocky Flats generated containers were examined by SRS in FY 2006 and 27 from Hanford (Table 3.4). As of July 2006, the FY 2006 sample evaluation was ongoing, and a complete summary of containers evaluated is not available.

\subsubsection{Judgmental Sample Selection for FY 2006}

Three judgmental samples were selected from SRS. Two of the originally selected SRS (FY 2005) containers were under International Atomic Energy Agency (IAEA) control and could not be sampled in FY 2005. These containers were substituted with other containers for the FY 2005 surveillance while efforts were made to remove them from IAEA control. The deferred containers were added back into the FY 2006 sample as judgmental samples. One additional judgmental sample was selected from the containers showing $\mathrm{HCl}$ in the Rocky Flats FTIR moisture analysis.

Six judgmental samples were selected by the MIS working group from Hanford containers. Two were from pure button-line oxide (BLO) that had unusually high water content, one from oxide from impure solutions with high water content, and three from containers with chloride salt packaged in the RMC line with high water content. 
Table 3.3. FY 2006 Surveillance Samples

\begin{tabular}{|c|c|c|c|c|}
\hline $\begin{array}{l}\text { Surveillance } \\
\text { Site }\end{array}$ & FY 2005 ISP Bin & FY 2006 ISP Bin & Surveillance Comment & $\begin{array}{c}3013 \\
\text { Container } \\
\text { ID }\end{array}$ \\
\hline \multirow[t]{24}{*}{ Hanford } & Innocuous & Innocuous & Random Sample & H003321 \\
\hline & \multirow[t]{14}{*}{ Pressure } & \multirow[t]{14}{*}{ Pressure } & \multirow[t]{12}{*}{ Random Sample } & H003062 \\
\hline & & & & H001386 \\
\hline & & & & H002823 \\
\hline & & & & H003833 \\
\hline & & & & H002166 \\
\hline & & & & H002180 \\
\hline & & & & H002352 \\
\hline & & & & H003779 \\
\hline & & & & H002771 \\
\hline & & & & H003049 \\
\hline & & & & H003098 \\
\hline & & & & H004649 \\
\hline & & & \multirow{2}{*}{$\begin{array}{l}\text { Judgmental Sample. Pure Oxide (BLO), } \\
\text { high } \mathrm{H}_{2} \mathrm{O}\end{array}$} & H001577 \\
\hline & & & & H002429 \\
\hline & \multirow[t]{9}{*}{ Pressure and Corrosion } & \multirow[t]{2}{*}{ Pressure } & Random Sample & H003094 \\
\hline & & & $\begin{array}{l}\text { Judgmental Sample. Oxide from impure } \\
\text { solutions, high } \mathrm{H}_{2} \mathrm{O}\end{array}$ & H001181 \\
\hline & & \multirow[t]{7}{*}{ Pressure and Corrosion } & \multirow[t]{4}{*}{ Random Sample } & H003807 \\
\hline & & & & H003598 \\
\hline & & & & H002468 \\
\hline & & & & H002869 \\
\hline & & & \multirow{3}{*}{$\begin{array}{l}\text { Judgmental Sample. With Cl salt, } \\
\text { packaged in RMC, high } \mathrm{H}_{2} \mathrm{O}\end{array}$} & H002565 \\
\hline & & & & H003181 \\
\hline & & & & H003655 \\
\hline \multicolumn{4}{|l|}{ Hanford Total } & 24 \\
\hline LLNL & Pressure and Corrosion & Pressure and Corrosion & Random Sample & L000172 \\
\hline \multicolumn{4}{|l|}{ LLNL Total } & 1 \\
\hline \multirow{22}{*}{$\begin{array}{l}\text { SRS (Rocky } \\
\text { Flats) }\end{array}$} & Innocuous & Pressure & Random Sample & R611336 \\
\hline & \multirow[t]{13}{*}{ Pressure } & \multirow[t]{13}{*}{ Pressure } & \multirow[t]{13}{*}{ Random Sample } & H000891 \\
\hline & & & & $\mathbf{R 6 0 0 1 8 3}$ \\
\hline & & & & R600445 \\
\hline & & & & R600498 \\
\hline & & & & R600833 \\
\hline & & & & R601309 \\
\hline & & & & R601571 \\
\hline & & & & R601997 \\
\hline & & & & R602477 \\
\hline & & & & R602662 \\
\hline & & & & R610247 \\
\hline & & & & R610601 \\
\hline & & & & R610876 \\
\hline & \multirow[t]{8}{*}{ Pressure and Corrosion } & \multirow[t]{2}{*}{ Pressure } & \multirow[t]{2}{*}{ Random Sample } & R601882 \\
\hline & & & & R610726 \\
\hline & & \multirow[t]{6}{*}{ Pressure and Corrosion } & \multirow[t]{3}{*}{ Random Sample } & R610898 \\
\hline & & & & R611017 \\
\hline & & & & R611328 \\
\hline & & & Judgmental Sample. FTIR shows $\mathrm{HCl}$ & R610910 \\
\hline & & & $\begin{array}{l}\text { Judgmental Sample. Oldest Container }> \\
10 \mathrm{gm} . \mathrm{H}_{2} \mathrm{O} \text { (Deferred FY05 sample) }\end{array}$ & R600151 \\
\hline & & & $\begin{array}{l}\text { Judgmental Sample. Maximum Pressure } \\
\text { Uncorrected } \mathrm{H}_{2} \mathrm{O} \text { (Deferred FY05 sample) }\end{array}$ & R600793 \\
\hline SRS (Rocky Flat & Total & & & 22 \\
\hline Grand Total & & & & 47 \\
\hline
\end{tabular}


Table 3.4. Additional NDE Samples in FY 2006

\begin{tabular}{|c|c|c|c|c|}
\hline Site of origin & FY 2005 ISP Bin & FY 2006 ISP Bin & Comment & $\begin{array}{c}3013 \\
\text { Container } \\
\text { ID } \\
\end{array}$ \\
\hline Rocky Flats & Innocuous & Pressure and Corrosion & Sample of opportunity & R611358 \\
\hline Rocky Flats & Pressure & Pressure & Sample of opportunity & R610465 \\
\hline Hanford & Pressure & Pressure & Oxide from impure solution - - High water & H001201 \\
\hline Hanford & Pressure & Pressure & Repeat from FY 2005 & H001892 \\
\hline Hanford & Pressure & Pressure & Repeat from FY 2005 & H002066 \\
\hline Hanford & Pressure and Corrosion & Pressure and Corrosion & ARF $>9$ grams water & H002509 \\
\hline Hanford & Pressure and Corrosion & Pressure and Corrosion & ARF with weight gain and like 011589A & $\mathrm{H} 002534$ \\
\hline Hanford & Pressure and Corrosion & Pressure and Corrosion & ARF with weight gain & $\mathrm{H} 002624$ \\
\hline Hanford & Pressure and Corrosion & Pressure and Corrosion & Special sample—like 011589A & $\mathrm{H} 002786$ \\
\hline Hanford & Pressure and Corrosion & Pressure and Corrosion & Special sample-like 011589A & H002809 \\
\hline Hanford & Pressure and Corrosion & Pressure and Corrosion & Special sample—-like 011589A & H002866 \\
\hline Hanford & Pressure and Corrosion & Pressure and Corrosion & C-line-high TGA & H003032 \\
\hline Hanford & Pressure and Corrosion & Pressure and Corrosion & Special sample-like 011589A & H003077 \\
\hline Hanford & Pressure and Corrosion & Pressure and Corrosion & Special sample—-like 011589A & H003343 \\
\hline Hanford & Pressure and Corrosion & Pressure and Corrosion & C-line-high TGA & H003352 \\
\hline Hanford & Pressure and Corrosion & Pressure and Corrosion & Special sample—like 011589A & H003626 \\
\hline Hanford & Pressure and Corrosion & Pressure and Corrosion & Special sample—like 011589A & H003695 \\
\hline Hanford & Pressure and Corrosion & Pressure and Corrosion & Repeat from FY 2005 & $\mathrm{H} 003716$ \\
\hline Hanford & Pressure and Corrosion & Pressure and Corrosion & $\mathrm{ARF}>9$ grams water & H003896 \\
\hline Hanford & Pressure and Corrosion & Pressure and Corrosion & Special sample—like 011589A & H003931 \\
\hline Hanford & Pressure and Corrosion & Pressure and Corrosion & Special sample-like 011589A & $\mathrm{H} 003940$ \\
\hline Hanford & Pressure and Corrosion & Pressure and Corrosion & Special sample—like 011589A & H003989 \\
\hline Hanford & Pressure and Corrosion & Pressure and Corrosion & Highest weight gain & H004099 \\
\hline Hanford & Pressure and Corrosion & Pressure and Corrosion & ARF with weight gain & H004102 \\
\hline Hanford & Pressure and Corrosion & Pressure and Corrosion & ARF $>9$ grams water & H004111 \\
\hline Hanford & Pressure and Corrosion & Pressure & Highest weight gain & H004117 \\
\hline Hanford & Pressure and Corrosion & Pressure and Corrosion & ARF with weight gain & H004153 \\
\hline Hanford & Pressure and Corrosion & Pressure and Corrosion & C-line-high TGA & H004179 \\
\hline Hanford & Pressure and Corrosion & Pressure and Corrosion & Special sample—like 011589A & H004232 \\
\hline Hanford & Pressure and Corrosion & Pressure and Corrosion & Special sample-like 011589A & H004233 \\
\hline
\end{tabular}

\subsection{Surveillance Samples for FY 2007}

Sample selection for FY 2007 surveillance activities was identified in FY 2006 using the revised binning results from FY 2006 (see Section 1 for binning results and Section 2 for the new statistical sample). The FY 2007 NDE sample consisted of a subset of the new FY 2006 statistical sample for the Pressure and Innocuous bins, minus the samples selected for FY 2005 and FY 2006 examination that were still in the random sample. The DE sample selection for FY 2007 consisted of random samples selected from the Pressure bin and Pressure and Corrosion bin statistical sample, and judgmental samples selected only from the Pressure and Corrosion bin. Random DE samples are required to be at least 5 years old at the time of evaluation. Engineering judgment considerations used for FY 2007 sample selection are discussed below.

\subsubsection{Summary of FY 2007 Container Selection}

Table 3.5 below lists the 36 containers selected for evaluation in FY 2007. Of these, 25 were randomly selected from the Pressure bin random sample, three were selected from the Pressure 
and Corrosion sample (the only containers in the random sample meeting the age requirement), two from the Innocuous bin sample, and four based on engineering judgment. The remaining two items were Pressure containers that will have DE. These two containers were in the 2005 random selection for the Pressure bin and were selected by engineering judgment.

Hanford is scheduled to evaluate 13 containers by NDE, and SRS is scheduled to evaluate 14 containers by NDE and 9 containers by DE. These containers satisfy the FY07 selection criteria required by the ISP steering Committee for the DOE complex. All randomly selected NDE and DE containers are required to be at least three years old and five years old, respectively, (from the inner can weld date) by the end of June 2006. This list is the minimum necessary to meet the requirements of the ISP. Additional containers may be evaluated as necessary by each site based on site-specific needs.

\subsubsection{Judgmental Sample Selection for FY 2007}

Results from the FY 2005 container NDE tests indicated that no pressurization above the established action limits was observed. ${ }^{30-32}$ The maximum container pressure observed by SRS surveillance was less than $10 \mathrm{psi}$, and no container integrity issues were found. ${ }^{26}$

Evaluation of the ongoing small-scale test program at LANL identified three MIS small-scale test samples that exhibit behavior that warrants further investigation. First, MIS item ARF-1085-223 (ARF-223) showed significant pitting corrosion of the small-scale test reactor with relatively high hydrogen generation. ${ }^{30}$ Second, as of August 2006, MIS item C06032A had the highest total gas generation of all MIS small-scale test samples. ${ }^{33}$ And third, MIS Item 011589A is generating both hydrogen and oxygen gas, which has reached flammable levels in the small-scale test reactor. ${ }^{34-36}$

Four judgmental samples were selected for DE analysis by members of the Engineering Review Team (a subset of the MIS Working Group) and are listed in Table 3.5. One container was selected based on similarity to MIS item ARF-223, one based on similarity to C06032A, and two containers based on similarity to MIS item 011589A. A strict time limit since packaging is not imposed for judgmental samples; however, time is one of the factors used in the selection process.

The two containers selected for DE analysis from the Pressure bin statistical sample were identified using engineering judgment (Appendix A-Table A-2) and meeting the requirement that they would be at least five years old by June 30, 2007. 
Table 3.5. DE and NDE Samples For FY 2007

\begin{tabular}{|c|c|c|c|c|c|}
\hline $\begin{array}{l}\text { Surveillance } \\
\text { Site ID }\end{array}$ & ISP Bin & $\begin{array}{c}\text { FY07 } \\
\text { Sample } \\
\text { Method }\end{array}$ & $\begin{array}{l}\text { FY } 07 \\
\text { sample } \\
\text { type }\end{array}$ & Surveillance Comment & $\begin{array}{c}3013 \\
\text { Container } \\
\text { ID }\end{array}$ \\
\hline Hanford & Pressure & $\mathrm{NDE}$ & Random & Random sample $>3$ yr. old & $\begin{array}{l}\text { H001373 } \\
\text { H001517 } \\
\text { H001527 } \\
\text { H001955 } \\
\text { H002145 } \\
\text { H002148 } \\
\text { H002153 } \\
\text { H002221 } \\
\text { H002716 } \\
\text { H003665 } \\
\text { H004304 } \\
\text { H004331 } \\
\text { H004590 }\end{array}$ \\
\hline \multicolumn{5}{|l|}{ Hanford Total } & 13 \\
\hline \multirow[t]{8}{*}{$\begin{array}{l}\text { SRS (Rocky } \\
\text { Flats) }\end{array}$} & Innocuous & NDE & Random & Random sample $>3$ yr. old & $\begin{array}{l}\text { H000872 } \\
\text { R610009 }\end{array}$ \\
\hline & \multirow[t]{2}{*}{ Pressure } & $\mathrm{DE}$ & Random & Random sample $>5$ yr. old & $\begin{array}{l}\mathrm{R} 600885 \dagger \\
\mathrm{R} 601722 \dagger\end{array}$ \\
\hline & & NDE & Random & Random sample $>3$ yr. old & $\begin{array}{l}\text { H000895 } \\
\text { R600320 } \\
\text { R600944 } \\
\text { R601318 } \\
\text { R601450 } \\
\text { R601569 } \\
\text { R602483 } \\
\text { R602804 } \\
\text { R610351 } \\
\text { R610809 } \\
\text { R611379 }\end{array}$ \\
\hline & \multirow{5}{*}{$\begin{array}{l}\text { Pressure and } \\
\text { Corrosion }\end{array}$} & \multirow[t]{5}{*}{$\mathrm{DE}$} & \multirow[t]{4}{*}{ Judgmental } & Like ARF-223, (Also from $\mathrm{HCl}$ plot) & R610697 \\
\hline & & & & Like C06032A, (Also from $\mathrm{HCl}$ plot) & R610735 \\
\hline & & & & Most Like 011589A & R602498 \\
\hline & & & & $\begin{array}{l}\text { Potentially like } 011589 \mathrm{~A}, \text { (Also from } \\
\mathrm{HCl} \text { plot) }\end{array}$ & R611398 \\
\hline & & & Random & Random sample $>5$ yr. old & $\begin{array}{l}\text { R600719 } \\
\text { R601285 } \\
\text { R601957 }\end{array}$ \\
\hline SRS (SRS) & Pressure & NDE & Random & Random sample $>3$ yr. old & S001669 \\
\hline \multicolumn{5}{|l|}{ SRS Total } & 23 \\
\hline \multicolumn{5}{|l|}{ Grand Total } & 36 \\
\hline
\end{tabular}

$\dagger$ R600885 and R601722 were nondestructively evaluated in FY 2005 


\subsection{Surveillance in FY 2008 and Beyond}

The recommended schedule for evaluation of all random samples is shown in Appendix A. The schedule is based on the minimum time since packaging and the surveillance rates specified in the Surveillance and Monitoring Plan. ${ }^{6}$ Containers in the Pressure and Corrosion bin should be evaluated destructively according to the schedule in Table A-1. Containers in the Pressure bin and Innocuous bin should be nondestructively examined according to the schedules in Tables A-2 and A-3, respectively. In addition, in FY 2008 and FY 2009, two containers per year from the Pressure bin will be selected for destructive examination based on engineering judgment. Sites may change the order that the random samples listed in tables A-1 through A-3 are selected for examination, as long as (1) they adhere to the $3 / 5$ year minimum age for NDE/DE respectively, and (2) they notify the MIS working group that they have changed the order.

Additional judgmental samples may be selected for either NDE or DE, based on results from field surveillances or MIS work. Any additional judgmental samples identified in the future will be documented in a letter from the MIS working group to the ISP Steering Committee and will be included in any future revisions to this document.

This document will be reviewed and revised as needed. For example, the number and binning of containers yet to be packaged was based on best engineering judgment. It is likely that when all materials are packaged and the data evaluated, the number of containers in each bin will change. Also, future prompt gamma measurements as well as reanalysis of prompt gamma data and reanalysis of TGA moisture data may result in bin assignment changes. These changes could affect sample specifications. In addition, the field surveillance activities will be reviewed at MIS meetings. As part of those reviews, NDE results, shelf-life data, and updated stabilization/packaging data will be analyzed to determine if the FY 2007 sample and/or future year sample selections require modification.

\section{Acknowledgement}

Contributions to this report were made through personal conversations, conference calls, and informal e-mails, between the authors and members of the MIS Working Group. Also, preliminary drafts of this report were reviewed and commented on by the MIS Working Group. The MIS Working Group site representatives are listed below.

Jennifer Burch, LLNL

Karen Dodson, LLNL

Richard Mason, LANL

James McClard, SRS

G. D. Roberson, DOE/AL

Richard W. Szempruch, Fluor Hanford

Jerry Stakebake, Consultant

Theodore J. Venetz, Fluor Hanford 


\section{References}

1. L. Peppers, E. Kelly, J. McClard, J. Stakebake, and T. Venetz, "Binning of 3013 Containers for Field Surveillance," Los Alamos National Laboratory report LA-14184 (June 2005).

2. E. Kelly, J. McClard, L. Peppers, J. Stakebake, and T. Venetz, "3013 Surveillance Sampling-The Statistical Sample,” Los Alamos National Laboratory report LA-14185 (June 2005).

3. L. Peppers, E. Kelly, K. Veirs, and J. Berg, "3013 Container Statistical and Judgmental Samples Selected for Non Destructive Evaluation (NDE) in FY 2005," Los Alamos National Laboratory document LA-UR-05-2193 (July 2005).

4. DOE, "Stabilization, Packaging, and Storage of Plutonium-Bearing Materials," DOE-STD-3013, U.S. Department of Energy.

5. "Integrated Surveillance Program in Support of Long-Term Storage of Plutonium-Bearing Materials," Los Alamos National Laboratory document LA-UR-00-3246, Rev. 1 (March 2001).

6. "Surveillance and Monitoring Plan for DOE-STD-3013 Materials," Westinghouse Savannah River Company report SR-NMPD-03-001, Rev. 0 (June 2003).

7. J.M. Berg, "Re-Analysis of RFETS PuSPS TGA-FTIR Moisture Measurement Data," Los Alamos National Laboratory document LA-UR-05-7395 (October 2005).

8. L. Peppers, D. Prochnow, J. Narlesky, and J. Watts, “Integrated Surveillance Program Database,” Los Alamos National Laboratory (Microsoft ${ }^{\circledR}$ Access database available electronically and classified SRD) (2002-2006).

9. T.J. Venetz, "PFP Material Representation in the Materials Identification and Surveillance Program," Fluor Hanford report HNF-14482, Rev. 0 (January 2003).

10. H.F. Dalton, "Rocky Flats Material Representation in the Materials Identification and Surveillance Program,” Department of Energy, Rocky Flats Field Office memorandum (May 7, 2001).

11. R. McNew, "FB-Line Material Representation in the Materials Identification and Surveillance Program," Westinghouse Savannah River Company report X-TR-F-00003, Revision 0 (October 2003).

12. J. Narlesky, "Lawrence Livermore Prompt Gamma—Final Report," Los Alamos National Laboratory document LA-UR-05-0755 (February 2006).

13. J. Narlesky, "Prompt Gamma Analysis of the Savannah River Site 3013 Containers-Final Report," Los Alamos National Laboratory document LA-UR-06-1245 (February 2006).

14. D.R. Spearing and W.J. Crooks, "Gas Generation Mechanisms in Pu Metal Bearing DOE-3013 Containers," Los Alamos National Laboratory document LA-UR-03-1214 (April 2003).

15. M.A. Williamson, "Plutonium Storage: Phase Equilibria Issues," Los Alamos National Laboratory document LA-UR-99-136 Draft (January 1999).

16. D.G. Kolman, "A Review Of The Potential Environmentally Assisted Failure Mechanisms Of Austenitic Stainless Steel Storage Containers Housing Stabilized Radioactive Compounds," Corrosion Science $\mathbf{4 3}$ (2001) 99-125.

17. A.J. Sedriks, Corrosion of Stainless Steels, John Wiley \& Sons, Inc., New York (1996).

18. P. Zapp and S. Lillard, "Review of Fluoride-Induced Corrosion of Austenitic Stainless Steel," Westinghouse Savannah River Company, Savannah River National Laboratory document SRNL-MTS-2005-50025 (October 2005).

19. K. Veirs, "Small-Scale Surveillance," Materials Identification and Surveillance (MIS) Conference Proceedings, Savannah River Site, South Carolina, Los Alamos National Laboratory document LA-UR-06-3404 (April 25-26, 2006).

20. J. Berg, L. Morales, M. Brugh, Y. Mazza, and G. S. Barney, “Observations of Hydrogen Chloride 
Evolution During TGA Analysis of Plutonium-Bearing Oxide Materials Stabilized in Conformance with DOE-STD-3013-2000,” Los Alamos National Laboratory document LA-UR-04-0654 (January 2004).

21. "Los Alamos National Laboratory Materials Stabilization Project-Project Execution Plan," Los Alamos National Laboratory document LA-UR-05-3271 (March 2005).

22. W.G. Cochran, Sampling Techniques, Third Edition (John Wiley \& Sons, New York 1977).

23. S-PLUS 6 for Windows, Insightful Corporation, Seattle, Washington, Copyright (C 1987-2001.

24. R. Szempruch, et al., "Resolution of Issues Associated with Digital Radiography of 3013 Containers," Fluor Hanford report NMS-19056, (March 2004).

25. T. Venetz, "PFP 3013 Surveillance," Materials Identification and Surveillance (MIS) Conference Proceedings, Albuquerque, New Mexico, Los Alamos National Laboratory document LA-UR-04-8813 (October 19-20, 2004).

26. T. Venetz, "Hanford FY05 Field Surveillance Activities in Support of the DOE Integrated Surveillance Program for DOE-STD-3013 Containers," Fluor Hanford report NMS-27644 (October 2005).

27. S.W. McAlhany, "Fiscal Year (FY) 2005 Non Destructive Examination List for Sites Storing DOE-STD3013 Containers," Department of Energy, Savannah River Operations Office memorandum NMPD-05-049, (January 27, 2005).

28. J. Berg, C. Delegard, D.K. Veirs, and P.G. Eller, "Evaluation of the Potential for $\mathrm{CO}_{2}$ Evolution from Plutonium-Bearing Oxide Materials Stabilized and Stored in Conformance With DOE-STD-3013-2000," Los Alamos National Laboratory document LA-UR-03-0811 (March 2003).

29. G.D. Roberson, "FY06 NDE Recommended Items,” Department of Energy, Albuquerque Operations Office memorandum to Allen Gunter, Integrated Surveillance Program Chair.

30. K.J. Durrwachter, K.A. Dunn, and J.W. McClard, “3013/9975 Surveillance Program Annual Summary Report (FY05)," Westinghouse Savannah River Company, Savannah River Site report WSRC-TR-2005-00422 (September 2005).

31. "The Savannah River Site Surveillance Program for the Storage of 9975 Plutonium Packages in KAMS," Westinghouse Savannah River Company report WSRC-TR-2001-00286, Revision 2.

32. D.K. Veirs, et al., "Gas Generation and Corrosion in Salt-Containing Impure Plutonium Oxide Materials: Initial Results for ARF-102-85-223," Los Alamos National Laboratory report LA-14148 (July 2004).

33. J.E. Narlesky, J.M. Berg, and D.K. Veirs, "Identification of 3013 Containers Represented by MIS Sample C06032A," Los Alamos National Laboratory document LA-UR-06-6460 (August 2006).

34. J.M. Berg, D.K. Veirs, and L.A. Worl, "Maximum Pressure for Structural Response Calculation of 3013 Containers," Los Alamos National Laboratory document LA-UR-06-4051 (June 2006).

35. G.D. Roberson, "Transmittal of Information Identified by the Surveillance and Monitoring Program Relating to DOE-STD-3013-2004," Department of Energy, Albuquerque Operations Office memorandum to Allen Gunter, Integrated Surveillance Program Chair, (June 22, 2006).

36. G.P. Friday and L.G. Peppers, "Investigation of MIS Item 011589A and 3013 Containers Having Similar Characteristics," Washington Savannah River Company, Savannah River National Laboratory report WSRC-TR-2006-00236 (August 2006). 


\section{Appendix A-Random Sample Based on FY 2006 Rebinning}

Table A-1 - Pressure and Corrosion Bin Random Sample

\begin{tabular}{|c|c|c|c|c|c|}
\hline Container ID & Site & FY06 Bin & FY06 Sub bin & $\begin{array}{c}\text { Inner Can } \\
\text { Date }\end{array}$ & DE Eval. Year \\
\hline R600719 & RFETS & Pressure and Corrosion & BDT-4-RF-2B & 14-Jan-02 & 2007 \\
\hline R601285 & RFETS & Pressure and Corrosion & BDT-3-Cl & 14-May-02 & 2007 \\
\hline R601957 & RFETS & Pressure and Corrosion & BDT-3-Cl & $19-F e b-02$ & 2007 \\
\hline H001885 & Hanford & Pressure and Corrosion & BDT-4-H-2B & 17-Nov-02 & 2008 \\
\hline H001916 & Hanford & Pressure and Corrosion & BDT-4-H-2B & 22-Aug-02 & 2008 \\
\hline H001941 & Hanford & Pressure and Corrosion & BDT-4-H-2B & $01-$ Oct-02 & 2008 \\
\hline H001992 & Hanford & Pressure and Corrosion & BDT-3-F & 11-Sep-02 & 2008 \\
\hline H003157 & Hanford & Pressure and Corrosion & BDT-3-F & 21-Oct-02 & 2008 \\
\hline H000898 & RFETS & Pressure and Corrosion & BDT-3-F & 18 -Dec-02 & 2008 \\
\hline R602731 & RFETS & Pressure and Corrosion & BDT-4-RF-2B & $10-$ Oct- 02 & 2008 \\
\hline R610298 & RFETS & Pressure and Corrosion & BDT-3-Cl & 13-Jan-03 & 2008 \\
\hline R610324 & RFETS & Pressure and Corrosion & BDT-3-Cl & $26-F e b-03$ & 2008 \\
\hline R610327 & RFETS & Pressure and Corrosion & ER-C5-HCl (No PG) & 02-Jan-03 & 2008 \\
\hline R610558 & RFETS & Pressure and Corrosion & BDT-3-F & 14-Apr-03 & 2008 \\
\hline R610578 & RFETS & Pressure and Corrosion & BDT-3-Cl & 08-Apr-03 & 2008 \\
\hline R610584 & RFETS & Pressure and Corrosion & BDT-3-F & 07-Apr-03 & 2008 \\
\hline H002195 & Hanford & Pressure and Corrosion & BDT-3-Cl & $03-F e b-03$ & 2009 \\
\hline H002200 & Hanford & Pressure and Corrosion & BDT-4-H-2B & $04-F e b-03$ & 2009 \\
\hline H002354 & Hanford & Pressure and Corrosion & BDT-4-H-2B & 11-Mar-03 & 2009 \\
\hline H002447 & Hanford & Pressure and Corrosion & BDT-4-H-1E & 12-May-03 & 2009 \\
\hline H003004 & Hanford & Pressure and Corrosion & BDT-4-H-2B & 10-Jun-03 & 2009 \\
\hline H003077 & Hanford & Pressure and Corrosion & BDT-3-Cl & 05-Jun-03 & 2009 \\
\hline H003367 & Hanford & Pressure and Corrosion & BDT-3-Cl & 18-Jun-03 & 2009 \\
\hline H003409 & Hanford & Pressure and Corrosion & BDT-3-Cl & 24-Jun-03 & 2009 \\
\hline R610573 & RFETS & Pressure and Corrosion & BDT-3-Cl & 15-Apr-03 & 2009 \\
\hline R610679 & RFETS & Pressure and Corrosion & BDT-3-F & 18-Apr-03 & 2009 \\
\hline R610700 & RFETS & Pressure and Corrosion & BDT-3-F & 18-Apr-03 & 2009 \\
\hline R610764 & RFETS & Pressure and Corrosion & BDT-3-Cl & 22-Apr-03 & 2009 \\
\hline R610806 & RFETS & Pressure and Corrosion & BDT-3-Cl & 16-Apr-03 & 2009 \\
\hline H002521 & Hanford & Pressure and Corrosion & BDT-3-Cl & 27-Jul-03 & 2010 \\
\hline H002553 & Hanford & Pressure and Corrosion & BDT-4-H-1E & 28-Jul-03 & 2010 \\
\hline H002554 & Hanford & Pressure and Corrosion & BDT-3-Cl & 24-Jul-03 & 2010 \\
\hline H002567 & Hanford & Pressure and Corrosion & BDT-4-H-1E & 23-Jul-03 & 2010 \\
\hline H002667 & Hanford & Pressure and Corrosion & BDT-3-Cl & 15-Jul-03 & 2010 \\
\hline H002728 & Hanford & Pressure and Corrosion & BDT-3-Cl & $25-J u n-03$ & 2010 \\
\hline H002750 & Hanford & Pressure and Corrosion & BDT-3-Cl & 08-Jul-03 & 2010 \\
\hline H002786 & Hanford & Pressure and Corrosion & BDT-4-H-1E & 09-Jul-03 & 2010 \\
\hline R610627 & RFETS & Pressure and Corrosion & BDT-3-Cl & 13-Мay-03 & 2010 \\
\hline R610712 & RFETS & Pressure and Corrosion & BDT-3-Cl & 13-Мay-03 & 2010 \\
\hline R610785 & RFETS & Pressure and Corrosion & BDT-3-Cl & 30-Apr-03 & 2010 \\
\hline R610826 & RFETS & Pressure and Corrosion & BDT-3-Cl & 13-Мay-03 & 2010 \\
\hline R610853 & RFETS & Pressure and Corrosion & BDT-3-Cl & 12-May-03 & 2010 \\
\hline H002592 & Hanford & Pressure and Corrosion & BDT-4-H-1E & 31-Jul-03 & 2011 \\
\hline $\mathrm{H} 002715$ & Hanford & Pressure and Corrosion & BDT-3-Cl & 05-Aug-03 & 2011 \\
\hline H003526 & Hanford & Pressure and Corrosion & BDT-3-Cl & 25-Aug-03 & 2011 \\
\hline H003565 & Hanford & Pressure and Corrosion & BDT-4-H-1E & 07-Sep-03 & 2011 \\
\hline
\end{tabular}




\begin{tabular}{|c|c|c|c|c|c|}
\hline Container ID & Site & FY06 Bin & FY06 Sub bin & $\begin{array}{c}\text { Inner Can } \\
\text { Date }\end{array}$ & DE Eval. Year \\
\hline H003613 & Hanford & Pressure and Corrosion & BDT-3-Cl & 11-Sep-03 & 2011 \\
\hline H003710 & Hanford & Pressure and Corrosion & BDT-3-Cl & 04-Sep-03 & 2011 \\
\hline $\mathrm{H} 003711$ & Hanford & Pressure and Corrosion & BDT-4-H-1E & 07-Sep-03 & 2011 \\
\hline H003720 & Hanford & Pressure and Corrosion & BDT-3-Cl & 31-Aug-03 & 2011 \\
\hline L000178 & LLNL & Pressure and Corrosion & BDT-4 (LLNL Washed) & 23-Jul-03 & 2011 \\
\hline R610960 & RFETS & Pressure and Corrosion & BDT-3-Cl & 15-May-03 & 2011 \\
\hline R610974 & RFETS & Pressure and Corrosion & BDT-3-Cl-HCl & 21-May-03 & 2011 \\
\hline R611131 & RFETS & Pressure and Corrosion & BDT-3-Cl & 03-Jun-03 & 2011 \\
\hline R611338 & RFETS & Pressure and Corrosion & BDT-3-Cl-HCl & 22-May-03 & 2011 \\
\hline H003326 & Hanford & Pressure and Corrosion & BDT-4-H-1E & 05 -Oct-03 & 2012 \\
\hline H003337 & Hanford & Pressure and Corrosion & BDT-3-Cl & 12 -Oct-03 & 2012 \\
\hline H003652 & Hanford & Pressure and Corrosion & BDT-4-H-1E & 14-Sep-03 & 2012 \\
\hline H003687 & Hanford & Pressure and Corrosion & BDT-4-H-1E & 28 -Sep-03 & 2012 \\
\hline $\mathrm{H} 003704$ & Hanford & Pressure and Corrosion & BDT-3-Cl & 21-Sep-03 & 2012 \\
\hline H003898 & Hanford & Pressure and Corrosion & BDT-4-H-1E & 28 -Oct-03 & 2012 \\
\hline H004048 & Hanford & Pressure and Corrosion & BDT-3-Cl & 04-Nov-03 & 2012 \\
\hline L000075 & LLNL & Pressure and Corrosion & BDT-4 (LLNL Washed) & 16-Jan-03 & 2012 \\
\hline R610906 & RFETS & Pressure and Corrosion & BDT-3-Cl & 06-Jun-03 & 2012 \\
\hline R610989 & RFETS & Pressure and Corrosion & BDT-3-Cl & 04-Jun-03 & 2012 \\
\hline R611019 & RFETS & Pressure and Corrosion & BDT-3-Cl-HCl & 06-Jun-03 & 2012 \\
\hline R611068 & RFETS & Pressure and Corrosion & BDT-3-Cl-HCl & 05-Jun-03 & 2012 \\
\hline S001721 & SRS & Pressure and Corrosion & BDT-3-Cl & 28-May-04 & 2012 \\
\hline H003970 & Hanford & Pressure and Corrosion & BDT-3-Cl & 13-Nov-03 & 2013 \\
\hline $\mathrm{H} 004010$ & Hanford & Pressure and Corrosion & BDT-3-Cl & 17-Nov-03 & 2013 \\
\hline H004012 & Hanford & Pressure and Corrosion & BDT-3-Cl & $05-\mathrm{Nov}-03$ & 2013 \\
\hline H004014 & Hanford & Pressure and Corrosion & BDT-4-H-1E & 17-Nov-03 & 2013 \\
\hline H004024 & Hanford & Pressure and Corrosion & BDT-4-H-1E & 14-Nov-03 & 2013 \\
\hline H004046 & Hanford & Pressure and Corrosion & BDT-3-Cl & $05-N o v-03$ & 2013 \\
\hline L000196 & LLNL & Pressure and Corrosion & BDT-4 (LLNL Washed) & 02-Oct-03 & 2013 \\
\hline L000202 & LLNL & Pressure and Corrosion & BDT-4 (LLNL Washed) & 05-Dec-03 & 2013 \\
\hline R610913 & RFETS & Pressure and Corrosion & BDT-3-Cl & 11-Jun-03 & 2013 \\
\hline R611189 & RFETS & Pressure and Corrosion & BDT-3-Cl & 11-Jun-03 & 2013 \\
\hline R611207 & RFETS & Pressure and Corrosion & BDT-3-Cl & 11-Jun-03 & 2013 \\
\hline R611328 & RFETS & Pressure and Corrosion & BDT-3-Cl & 26-Jun-03 & 2013 \\
\hline S001150 & SRS & Pressure and Corrosion & BDT-4-SR-ARF & 18 -Oct-04 & 2013 \\
\hline H003910 & Hanford & Pressure and Corrosion & BDT-3-Cl & 19-Nov-03 & 2014 \\
\hline H004100 & Hanford & Pressure and Corrosion & BDT-3-Cl & 19-Nov-03 & 2014 \\
\hline H004104 & Hanford & Pressure and Corrosion & BDT-3-Cl & $20-N o v-03$ & 2014 \\
\hline H004152 & Hanford & Pressure and Corrosion & BDT-3-Cl & 23-Nov-03 & 2014 \\
\hline H004164 & Hanford & Pressure and Corrosion & BDT-3-Cl & 23-Nov-03 & 2014 \\
\hline H004173 & Hanford & Pressure and Corrosion & BDT-3-Cl & 04-Dec-03 & 2014 \\
\hline Future & LANL & Pressure and Corrosion & Future & 30-Jun-08 & 2014 \\
\hline L000172 & LLNL & Pressure and Corrosion & BDT-4 (LLNL Washed) & 03-Jul-03 & 2014 \\
\hline L000223 & LLNL & Pressure and Corrosion & BDT-3-Cl & 12-Feb-04 & 2014 \\
\hline R610728 & RFETS & Pressure and Corrosion & BDT-4-RF-2B & 18-Jun-03 & 2014 \\
\hline R611402 & RFETS & Pressure and Corrosion & BDT-3-Cl & 20-Jun-03 & 2014 \\
\hline S002160 & SRS & Pressure and Corrosion & BDT-4-SR-ARF & 31-Oct-04 & 2014 \\
\hline S002288 & SRS & Pressure and Corrosion & BDT-3-Cl & 23-Oct-04 & 2014 \\
\hline H003307 & Hanford & Pressure and Corrosion & BDT-3-Cl & 10-Dec-03 & 2015 \\
\hline H004213 & Hanford & Pressure and Corrosion & BDT-3-Cl & 07-Dec-03 & 2015 \\
\hline H004220 & Hanford & Pressure and Corrosion & BDT-4-H-1E & 10 -Dec-03 & 2015 \\
\hline
\end{tabular}




\begin{tabular}{|c|c|c|c|c|c|}
\hline Container ID & Site & FY06 Bin & FY06 Sub bin & $\begin{array}{c}\text { Inner Can } \\
\text { Date }\end{array}$ & DE Eval. Year \\
\hline H004231 & Hanford & Pressure and Corrosion & BDT-3-Cl & 10-Dec-03 & 2015 \\
\hline H004248 & Hanford & Pressure and Corrosion & BDT-3-Cl & $08-$ Dec-03 & 2015 \\
\hline H004251 & Hanford & Pressure and Corrosion & BDT-3-Cl & $10-$ Dec-03 & 2015 \\
\hline Future & LANL & Pressure and Corrosion & Future & 30-Jun-08 & 2015 \\
\hline Future & LLNL & Pressure and Corrosion & Future & 30-Jun-08 & 2015 \\
\hline Future & LLNL & Pressure and Corrosion & Future & 30-Jun-08 & 2015 \\
\hline Future & LLNL & Pressure and Corrosion & Future & 30-Jun-08 & 2015 \\
\hline R611309 & RFETS & Pressure and Corrosion & BDT-4-RF-2B & 24-Jun-03 & 2015 \\
\hline R611417 & RFETS & Pressure and Corrosion & BDT-3-Cl & $25-J u n-03$ & 2015 \\
\hline S002132 & SRS & Pressure and Corrosion & BDT-4-SR-ARF & 03-Nov-04 & 2015 \\
\hline H002809 & Hanford & Pressure and Corrosion & BDT-3-Cl & 01-Jan-04 & 2016 \\
\hline H003052 & Hanford & Pressure and Corrosion & BDT-4-H-1E & 29-Dec-03 & 2016 \\
\hline H003064 & Hanford & Pressure and Corrosion & BDT-3-Cl & 08-Jan-04 & 2016 \\
\hline $\mathrm{H} 003276$ & Hanford & Pressure and Corrosion & BDT-3-Cl & 01-Jan-04 & 2016 \\
\hline H003313 & Hanford & Pressure and Corrosion & BDT-3-Cl & 12-Dec-03 & 2016 \\
\hline H004219 & Hanford & Pressure and Corrosion & BDT-3-Cl & 14-Dec-03 & 2016 \\
\hline Future & LANL & Pressure and Corrosion & Future & 30-Jun-08 & 2016 \\
\hline Future & LLNL & Pressure and Corrosion & Future & 30-Jun-08 & 2016 \\
\hline Future & LLNL & Pressure and Corrosion & Future & 30-Jun-08 & 2016 \\
\hline R611306 & RFETS & Pressure and Corrosion & BDT-4-RF-2B & 30-Jun-03 & 2016 \\
\hline R611376 & RFETS & Pressure and Corrosion & BDT-3-Cl & 02-Jul-03 & 2016 \\
\hline S002116 & SRS & Pressure and Corrosion & BDT-3-Cl & 13-Nov-04 & 2016 \\
\hline S002220 & SRS & Pressure and Corrosion & BDT-3-F & 23-Dec-04 & 2016 \\
\hline H002826 & Hanford & Pressure and Corrosion & BDT-3-Cl & 20-Jan-04 & 2017 \\
\hline H002862 & Hanford & Pressure and Corrosion & BDT-3-F & 14-Jan-04 & 2017 \\
\hline H003181 & Hanford & Pressure and Corrosion & BDT-4-H-1E & 08-Jan-04 & 2017 \\
\hline H003280 & Hanford & Pressure and Corrosion & BDT-3-F & 21-Jan-04 & 2017 \\
\hline H003312 & Hanford & Pressure and Corrosion & BDT-4-H-1E & 23-Dec-03 & 2017 \\
\hline H003625 & Hanford & Pressure and Corrosion & BDT-3-Cl & $03-$ Sep-03 & 2017 \\
\hline Future & LANL & Pressure and Corrosion & Future & 30-Jun-08 & 2017 \\
\hline Future & LLNL & Pressure and Corrosion & Future & 30-Jun-08 & 2017 \\
\hline Future & LLNL & Pressure and Corrosion & Future & 30-Jun-08 & 2017 \\
\hline R611101 & RFETS & Pressure and Corrosion & BDT-3-Cl-HCl & 08-Jul-03 & 2017 \\
\hline S002250 & SRS & Pressure and Corrosion & BDT-3-F & 08-Jan-05 & 2017 \\
\hline
\end{tabular}

Note: Four containers from LANL and seven from LLNL have not been specified as of August, 2006. LANL currently forecasts thirty Pressure and Corrosion containers, and LLNL estimates that they will produce another sixty-one containers. The remaining LANL and LLNL random sample containers will be selected from these containers. 
Table A-2 - Pressure Bin Random Sample

\begin{tabular}{|c|c|c|c|c|c|}
\hline Container ID & Site & FY06 Bin & FY06 Sub bin & $\begin{array}{c}\text { Inner Can } \\
\text { Date }\end{array}$ & $\begin{array}{c}\text { NDE Eval } \\
\text { Year }\end{array}$ \\
\hline $\mathrm{H} 001003$ & Hanford & Pressure & BDT-5 & 20-Dec-01 & 2005 \\
\hline H001201 & Hanford & Pressure & BDT-5 & 15-May-02 & 2005 \\
\hline H001295 & Hanford & Pressure & BDT-5 & 20-Nov-01 & 2005 \\
\hline H001464 & Hanford & Pressure & ER-C3 & 28-Jul-02 & 2005 \\
\hline H001542 & Hanford & Pressure & BDT-5 & 13-Nov-02 & 2005 \\
\hline H001844 & Hanford & Pressure & BDT-5 & 12-Nov-02 & 2005 \\
\hline H001892 & Hanford & Pressure & BDT-5 & 29-Oct-02 & 2005 \\
\hline H001925 & Hanford & Pressure & BDT-5 & 25-Nov-02 & 2005 \\
\hline H001948 & Hanford & Pressure & BDT-5 & 01-Oct-02 & 2005 \\
\hline H002019 & Hanford & Pressure & BDT-5 & 1-Oct-02 & 2005 \\
\hline H002066 & Hanford & Pressure & BDT-5 & 29-Oct-02 & 2005 \\
\hline H002615 & Hanford & Pressure & BDT-5 & 5-Jan-03 & 2005 \\
\hline H002670 & Hanford & Pressure & BDT-5 & 30-Dec-02 & 2005 \\
\hline L000206 & LLNL & Pressure & ER-C3 & 22-Dec-03 & 2005 \\
\hline H000906 & RFETS & Pressure & ER-C3 (Low F) & 04-Mar-03 & 2005 \\
\hline R600212 & RFETS & Pressure & BDT-5 & 26-Apr-02 & 2005 \\
\hline R600361 & RFETS & Pressure & BDT-5 & 03-Apr-02 & 2005 \\
\hline R600453 & RFETS & Pressure & BDT-5 & 09-May-02 & 2005 \\
\hline R600483 & RFETS & Pressure & BDT-5 & 11-Apr-02 & 2005 \\
\hline R600885† & RFETS & Pressure & BDT-5 & $27-F e b-02$ & 2005 \\
\hline R601356 & RFETS & Pressure & BDT-5 & 03-Jun-02 & 2005 \\
\hline R601451 & RFETS & Pressure & BDT-5 & 17-Oct-01 & 2005 \\
\hline R601456 & RFETS & Pressure & BDT-5 & 13-Nov-01 & 2005 \\
\hline $\mathrm{R} 601722 \dagger$ & RFETS & Pressure & BDT-5 & 20-Feb-02 & 2005 \\
\hline R601829 & RFETS & Pressure & BDT-5 & 09-Jan-02 & 2005 \\
\hline R601941 & RFETS & Pressure & BDT-5 & 28-Jan-02 & 2005 \\
\hline R602040 & RFETS & Pressure & BDT-5 & $15-F e b-02$ & 2005 \\
\hline R602072 & RFETS & Pressure & BDT-5 & 22-Jan-02 & 2005 \\
\hline H001386 & Hanford & Pressure & BDT-5 & 18-Jul-02 & 2006 \\
\hline H002166 & Hanford & Pressure & BDT-5 & 23-Jan-03 & 2006 \\
\hline H002180 & Hanford & Pressure & BDT-5 & 23-Jan-03 & 2006 \\
\hline H002352 & Hanford & Pressure & BDT-5 & 3-Apr-03 & 2006 \\
\hline H002771 & Hanford & Pressure & BDT-5 & 22-Jun-03 & 2006 \\
\hline H002823 & Hanford & Pressure & BDT-5 & 28-Dec-03 & 2006 \\
\hline H003049 & Hanford & Pressure & BDT-5 & 11-Jun-03 & 2006 \\
\hline H003062 & Hanford & Pressure & BDT-5 & 15-Jan-04 & 2006 \\
\hline H003094 & Hanford & Pressure & ER-C3 & 13-Jan-04 & 2006 \\
\hline H003098 & Hanford & Pressure & BDT-5 & 17-Jun-03 & 2006 \\
\hline H003779 & Hanford & Pressure & BDT-5 & 6-Oct-03 & 2006 \\
\hline H003833 & Hanford & Pressure & BDT-5 & 5-Oct-03 & 2006 \\
\hline Н004649 & Hanford & Pressure & BDT-5 & 25 -Sep-01 & 2006 \\
\hline H000891 & RFETS & Pressure & ER-C4-P & 06-Feb-03 & 2006 \\
\hline R600183 & RFETS & Pressure & BDT-5 & 02-Nov-01 & 2006 \\
\hline R600445 & RFETS & Pressure & BDT-5 & 03-Apr-02 & 2006 \\
\hline
\end{tabular}




\begin{tabular}{|c|c|c|c|c|c|}
\hline Container ID & Site & FY06 Bin & FY06 Sub bin & $\begin{array}{c}\text { Inner Can } \\
\text { Date }\end{array}$ & $\begin{array}{c}\text { NDE Eval } \\
\text { Year }\end{array}$ \\
\hline R600498 & RFETS & Pressure & BDT-5 & 11-Mar-02 & 2006 \\
\hline R600833 & RFETS & Pressure & BDT-5 & 11-Apr-02 & 2006 \\
\hline R601309 & RFETS & Pressure & ER-C2-P & 26-Jul-02 & 2006 \\
\hline R601571 & RFETS & Pressure & BDT-5 & 07-May-02 & 2006 \\
\hline R601997 & RFETS & Pressure & BDT-5 & 19-Aug-02 & 2006 \\
\hline R602477 & RFETS & Pressure & BDT-5 & 04-Oct-02 & 2006 \\
\hline R602662 & RFETS & Pressure & ER-C3 & 27-Aug-02 & 2006 \\
\hline R610247 & RFETS & Pressure & ER-C3 & $11-$ Feb-03 & 2006 \\
\hline R610601 & RFETS & Pressure & ER-C3 & 31-Mar-03 & 2006 \\
\hline R610726 & RFETS & Pressure & BDT-5 & 28-Apr-03 & 2006 \\
\hline R610876 & RFETS & Pressure & ER-C3 & 09-May-03 & 2006 \\
\hline $\mathrm{H} 001373$ & Hanford & Pressure & BDT-5 & 24-Jun-02 & 2007 \\
\hline H001517 & Hanford & Pressure & BDT-5 & 7-Aug-02 & 2007 \\
\hline H001527 & Hanford & Pressure & BDT-5 & 25-Jul-02 & 2007 \\
\hline H001955 & Hanford & Pressure & BDT-5 & 16-Dec-02 & 2007 \\
\hline H002145 & Hanford & Pressure & BDT-5 & 27-Jan-03 & 2007 \\
\hline H002148 & Hanford & Pressure & BDT-5 & 20-Jan-03 & 2007 \\
\hline H002153 & Hanford & Pressure & BDT-5 & 6-Mar-03 & 2007 \\
\hline H002221 & Hanford & Pressure & BDT-5 & 4-Feb-03 & 2007 \\
\hline $\mathrm{H} 002716$ & Hanford & Pressure & ER-C2-P (Low F) & 27-Aug-03 & 2007 \\
\hline H003665 & Hanford & Pressure & BDT-5 & 14-Sep-03 & 2007 \\
\hline H004304 & Hanford & Pressure & BDT-5 & 15-Jan-04 & 2007 \\
\hline H004331 & Hanford & Pressure & ER-C3 & 21-Jan-04 & 2007 \\
\hline H004590 & Hanford & Pressure & BDT-5 & 7-Sep-01 & 2007 \\
\hline H000895 & RFETS & Pressure & BDT-5 & 21-Jan-03 & 2007 \\
\hline R600320 & RFETS & Pressure & BDT-5 & 11-Mar-02 & 2007 \\
\hline R600944 & RFETS & Pressure & BDT-5 & 15-Apr-02 & 2007 \\
\hline R601318 & RFETS & Pressure & BDT-5 & 20-Мау-02 & 2007 \\
\hline R601450 & RFETS & Pressure & BDT-5 & 18-Sep-01 & 2007 \\
\hline R601569 & RFETS & Pressure & BDT-5 & 10-Sep-01 & 2007 \\
\hline R602483 & RFETS & Pressure & BDT-5 & 31-Jul-02 & 2007 \\
\hline R602804 & RFETS & Pressure & BDT-5 & $03-$-Oct-02 & 2007 \\
\hline R610351 & RFETS & Pressure & ER-C3 & 09-Jan-03 & 2007 \\
\hline R610809 & RFETS & Pressure & ER-C3 & 16-Apr-03 & 2007 \\
\hline R611379 & RFETS & Pressure & ER-C1-P & 20-May-03 & 2007 \\
\hline S001669 & SRS & Pressure & BDT-5 & 07-Jun-04 & 2007 \\
\hline H001198 & Hanford & Pressure & ER-C4-P (No PG) & 29-Jul-02 & 2008 \\
\hline H001221 & Hanford & Pressure & BDT-5 & 20-May-02 & 2008 \\
\hline $\mathrm{H} 001803$ & Hanford & Pressure & BDT-5 & 4-Nov-02 & 2008 \\
\hline H001920 & Hanford & Pressure & BDT-5 & 12-Nov-02 & 2008 \\
\hline H001936 & Hanford & Pressure & BDT-5 & 26-Nov-02 & 2008 \\
\hline H001968 & Hanford & Pressure & BDT-5 & 17-Nov-02 & 2008 \\
\hline H002039 & Hanford & Pressure & BDT-5 & 30-Jan-03 & 2008 \\
\hline H002088 & Hanford & Pressure & BDT-5 & 6-Nov-02 & 2008 \\
\hline H002258 & Hanford & Pressure & BDT-5 & 6-Feb-03 & 2008 \\
\hline H002291 & Hanford & Pressure & ER-C2-P & 09-Apr-03 & 2008 \\
\hline
\end{tabular}




\begin{tabular}{|c|c|c|c|c|c|}
\hline Container ID & Site & FY06 Bin & FY06 Sub bin & $\begin{array}{c}\text { Inner Can } \\
\text { Date } \\
\end{array}$ & $\begin{array}{c}\text { NDE Eval } \\
\text { Year }\end{array}$ \\
\hline H004695 & Hanford & Pressure & BDT-5 & 02-Sep-01 & 2008 \\
\hline R600330 & RFETS & Pressure & BDT-5 & 11-Nov-01 & 2008 \\
\hline R600503 & RFETS & Pressure & BDT-5 & 02-Apr-02 & 2008 \\
\hline R600565 & RFETS & Pressure & BDT-5 & 10-May-02 & 2008 \\
\hline R600802 & RFETS & Pressure & BDT-5 & 05-Mar-02 & 2008 \\
\hline R600927 & RFETS & Pressure & BDT-5 & 09-Apr-02 & 2008 \\
\hline R601106 & RFETS & Pressure & BDT-5 & 11-Apr-02 & 2008 \\
\hline R601577 & RFETS & Pressure & BDT-5 & 06-Feb-02 & 2008 \\
\hline R601627 & RFETS & Pressure & BDT-5 & 13-Sep-01 & 2008 \\
\hline R602223 & RFETS & Pressure & BDT-5 & 02-Мay-02 & 2008 \\
\hline R602577 & RFETS & Pressure & BDT-5 & 16-May-02 & 2008 \\
\hline S001543 & SRS & Pressure & BDT-5 & 23-Feb-04 & 2008 \\
\hline S001579 & SRS & Pressure & BDT-5 & 23-Jan-04 & 2008 \\
\hline S001682 & SRS & Pressure & BDT-5 & 20-Jul-04 & 2008 \\
\hline S001750 & SRS & Pressure & BDT-5 & 06-Jul-04 & 2008 \\
\hline H002385 & Hanford & Pressure & ER-C2-E-P & 21-May-03 & 2009 \\
\hline H002444 & Hanford & Pressure & BDT-5 & 20-May-03 & 2009 \\
\hline H001614 & Hanford & Pressure & BDT-5 & 22-Jan-03 & 2009 \\
\hline H003119 & Hanford & Pressure & BDT-5 & 19-Jan-04 & 2009 \\
\hline H003166 & Hanford & Pressure & ER-C2-P & 23-Dec-03 & 2009 \\
\hline H003593 & Hanford & Pressure & BDT-5 & 24-Sep-03 & 2009 \\
\hline H003684 & Hanford & Pressure & ER-C3 & 10-Sep-03 & 2009 \\
\hline H003709 & Hanford & Pressure & BDT-5 & 21-Sep-03 & 2009 \\
\hline H003809 & Hanford & Pressure & ER-C2-P & $06-O c t-03$ & 2009 \\
\hline H003824 & Hanford & Pressure & ER-C2-P & 3-Nov-03 & 2009 \\
\hline H001917 & Hanford & Pressure & BDT-5 & 14-Oct-02 & 2009 \\
\hline Future & LANL & Pressure & Future & 30-Jun-06 & 2009 \\
\hline H000529 & RFETS & Pressure & ER-C3 & 18-Feb-03 & 2009 \\
\hline H000841 & RFETS & Pressure & ER-C1-P & 13-Feb-03 & 2009 \\
\hline H000861 & RFETS & Pressure & ER-C3 (Low F) & $12-F e b-03$ & 2009 \\
\hline R600219 & RFETS & Pressure & BDT-5 & 09-Oct-02 & 2009 \\
\hline R601887 & RFETS & Pressure & BDT-5 & 01-Aug-02 & 2009 \\
\hline R602729 & RFETS & Pressure & BDT-5 & 01-Oct-02 & 2009 \\
\hline R610062 & RFETS & Pressure & BDT-5 & 09-Oct-02 & 2009 \\
\hline R610152 & RFETS & Pressure & ER-C3 & 17-Jan-03 & 2009 \\
\hline R610984 & RFETS & Pressure & ER-C3 & 16-Мay-03 & 2009 \\
\hline R611284 & RFETS & Pressure & ER-C3 & 26-Jun-03 & 2009 \\
\hline S001671 & SRS & Pressure & BDT-5 & 30-Jul-04 & 2009 \\
\hline S001780 & SRS & Pressure & BDT-5 & 28-Aug-04 & 2009 \\
\hline S002226 & SRS & Pressure & ER-C2-P (Low F) & 09-Jan-05 & 2009 \\
\hline
\end{tabular}

${ }^{\dagger}$ Containers R601722 and R600885 were selected for DE evaluation in FY 2007

NOTE: one container from LANL has not been specified. It will be selected randomly from those packaged as of August 2006 (current estimate is 18 containers) 
Table A-3 - Innocuous Bin Random Sample

\begin{tabular}{|c|c|c|c|c|c|}
\hline $\begin{array}{c}\text { Container } \\
\text { ID }\end{array}$ & Site & FY06 Bin & FY06 Sub bin & $\begin{array}{c}\text { Inner Can } \\
\text { Date }\end{array}$ & $\begin{array}{c}\text { Evaluation } \\
\text { Date }\end{array}$ \\
\hline \multicolumn{6}{|l|}{ Fluoride } \\
\hline R610192 & RFETS & Innocuous & ER-C2-I (Low F) & $3 / 7 / 2003$ & 2005 \\
\hline H000872 & RFETS & Innocuous & ER-C2-I (Low F) & $12 / 30 / 2002$ & 2007 \\
\hline \multicolumn{6}{|l|}{ ER - No F } \\
\hline H001189 & Hanford & Innocuous & ER-C4-I & $5 / 9 / 2002$ & 2005 \\
\hline H002097 & Hanford & Innocuous & ER-BDT-6-I (No PG) & $12 / 26 / 2002$ & 2008 \\
\hline R610009 & RFETS & Innocuous & ER-C2-I & $11 / 11 / 2002$ & 2007 \\
\hline H003321 & Hanford & Innocuous & ER-BDT-6-I (No PG) & $11 / 2 / 2003$ & 2006 \\
\hline S001178 & SRS & Innocuous & ER-C1-I & $12 / 20 / 2004$ & 2009 \\
\hline \multicolumn{6}{|l|}{ No - ER } \\
\hline R601574 & RFETS & Innocuous & BDT-6 & $8 / 4 / 2002$ & 2005 \\
\hline H002034 & Hanford & Innocuous & BDT-6 & $10 / 20 / 2002$ & 2008 \\
\hline S001756 & SRS & Innocuous & BDT-6 & $9 / 14 / 2004$ & 2009 \\
\hline
\end{tabular}


This report has been reproduced directly from the best available copy. It is available electronically on the Web (http://www.doe.gov/bridge).

Copies are available for sale to U.S. Department of Energy employees and contractors from:

Office of Scientific and Technical Information

P.O. Box 62

Oak Ridge, TN 37831

(865) 576-8401

Copies are available for sale to the public from: National Technical Information Service

U.S. Department of Commerce

5285 Port Royal Road

Springfield, VA 22161

(800) 553-6847 
- Los Alamos NATIONAL LABORATORY

EST.1943 